\title{
Visual Comfort in Modern University Classrooms
}

\author{
Yun-Shang Chiou *, Satryo Saputro and Dany Perwita Sari \\ Department of Architecture, National Taiwan University of Science and Technology, Taipei 106, Taiwan; \\ satryo.saputro@gmail.com (S.S.); dany.perwitasari@gmail.com (D.P.S.) \\ * Correspondence: ychiou@mail.ntust.edu.tw
}

Received: 23 March 2020; Accepted: 4 May 2020; Published: 11 May 2020

check for updates

\begin{abstract}
Universities are at the front line of promoting sustainability. The wellbeing of its students plays a key role in advancing such agendas. In the past decade, many university classrooms have been equipped with a projector; however, the lighting design of the classroom remains unchanged. This paper presents a visual comfort study of modern university classrooms by considering three working surfaces: the student's desk, whiteboard, and projector screen. The study cross-examines the quality of the classroom lighting by high dynamic range image (HDRi) photography and the students' well-being from user satisfaction surveys. Comparisons are organized based on the seating area of the student, the type of learning (text-based or image-based) in the classroom, and the lighting scene with and without a projector in use. The spot illuminance, luminance, HDRi spatial luminance distribution and the Unified Glare Rating (UGR) are the parameters used to describe lighting quality. This paper found that more than $70 \%$ of the respondents experienced some adverse physical symptoms, and nearly $50 \%$ felt that the lighting condition was not ideal for task performance. UGR indicated the presence of minor glare problems in whiteboard-based teaching scenarios, and daylight was too strong to be utilized. The results suggest that the lighting design needs to involve a luminance distribution minded approach for the students' wellbeing in classroom learning.
\end{abstract}

Keywords: visual comfort; lighting design; working surface; classroom; High dynamic range image (HDRi) luminance analysis

\section{Introduction}

Classrooms play an important role in human society. Students sit for up to $70 \%$ of a school day [1] and spend significantly more time in a classroom than not in a classroom. Over the last two decades, a combination of tools for teaching has slowly begun to replace traditional tools in classrooms. Traditional classrooms in universities usually focus on only writing instruction. To better meet the needs of 21st century learners, universities are adapting their teaching methods and modifying classroom equipment with new educational tools. In Taiwan, these tools are a combination of projectors, whiteboards and desks. Therefore, there are three surfaces that users focus on, the desk (horizontal-task surface) and the whiteboard and projection screen (both vertical-task surfaces). Due to the need to receive information during lecture sessions, users need to constantly switch among these three surfaces; thus, a static glare measurement may not be suitable in this case. Frequently, these activities are carried out at the same time. The distribution of different luminances in the classroom affects task visibility and visual comfort [2]. Visual comfort in educational buildings is an important issue. It is directly related to students' wellbeing and learning [3,4]. Studies have found that lighting design can have an immediate effect on students' visual comfort $[5,6]$.

Field Measurement and questionnaire survey are two common methods for lighting quality research $[7,8]$. Several instrumental measurements are available to evaluate various lighting conditions. Luminance is one measurement that integrates light energy in the visible region with spectral 
sensitivity to the human visual system [9]. It is favored over illuminance to describe the brightness of a space [10,11]. Luminance is widely applied for measures of direct visual stimulation and performance [9]. The development of high dynamic range image (HDRi) techniques in recent years has made the measurement of spatial luminance distribution feasible. The above techniques have further expanded the application of luminance-based lighting condition appraisals [2,12].

On the other hand, the user's response to the lighting condition can be categorized in several aspects for better comprehension. To do so, survey questionnaires should include the influences of lighting condition on the physiological symptoms, brightness perceptions and task performance of the users [13]. The combination of measurements and questionnaires provides a more complete appraisal of the classroom lighting quality.

The scenarios for the lighting condition analysis include the following: 1) Visual comfort level of the user at different seating locations; 2) Different media being used in a classroom (projector and whiteboard);3) different content of the classroom's material (text-based and image-based); and 4) A comparison between the glare metrics and actual comfort survey. Findings of this study were also compared to those from the literatures $[3,14,15]$ with similar lighting quality indicators. It helped to verify if they exhibit characteristics in accord with the others. Finally, this paper summarizes the issues of current classroom lighting design and possible economically minded remedies.

\section{Methodology}

This research is carried out with a two-pronged approach: luminance mapping using the HDRi photography technique (real-scene luminance capture) and a visual comfort survey using a questionnaire (user's opinion and feedback). The flow of operation is shown in Figure 1.

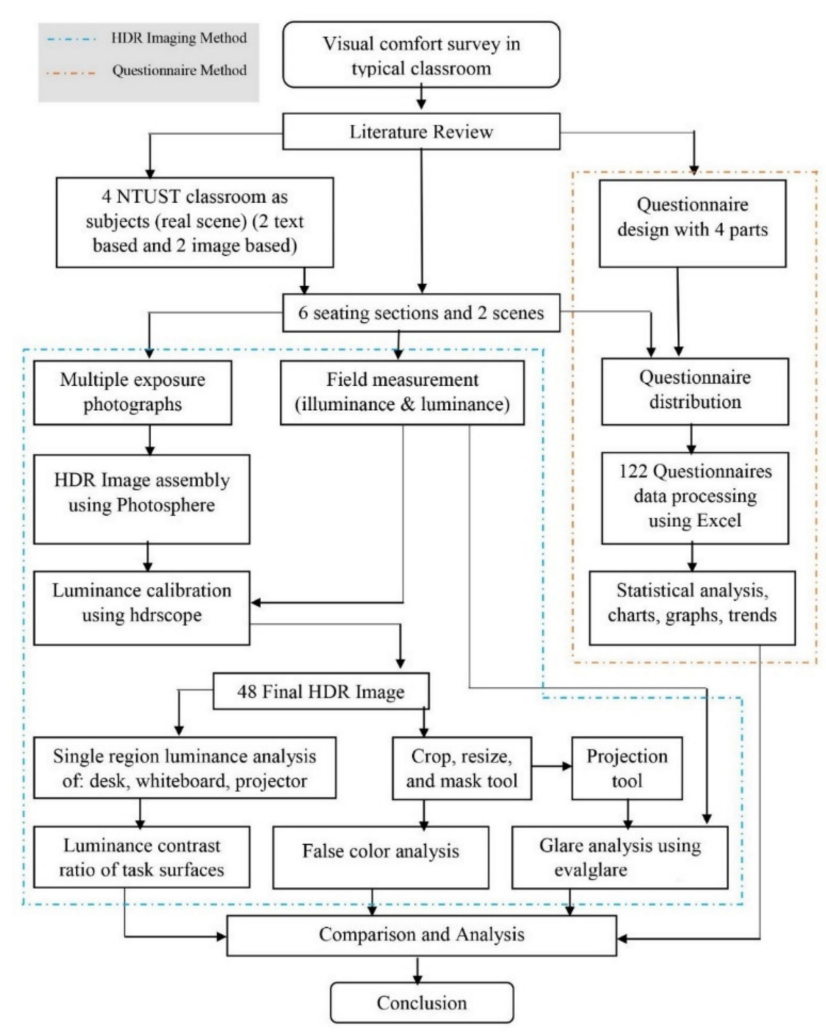

Figure 1. Flow of HDRi luminance mapping and questionnaires.

\subsection{Subject Classroom}

Four classrooms in the TR Building of the National Taiwan University of Science and Technology (NTUST), Taipei, Taiwan, were chosen for this study. The details of the selected classrooms are listed in 
Tables 1 and 2 and Figure 2. Two criteria were considered for the selection. The first criterion was the type of lecture. Classroom subjects were divided into two groups based on their content: text-based and image-based. A class was categorized as text-based if the lecture content was made up of mostly alphanumerical characters, such as letters, numbers, and symbols. Text-based classes include classes such as mathematics, physics, and linguistics. A class was categorized as image-based if the lecture content was made up of mostly graphs, images, and pictures. Image-based classes include classes such as art appreciation, architecture, and graphic design. The second criterion was the minimum number of students. Since this study used a questionnaire survey, the classrooms had to have at least 20 students. Therefore, a sufficient number of user responses could be collected for further analysis.

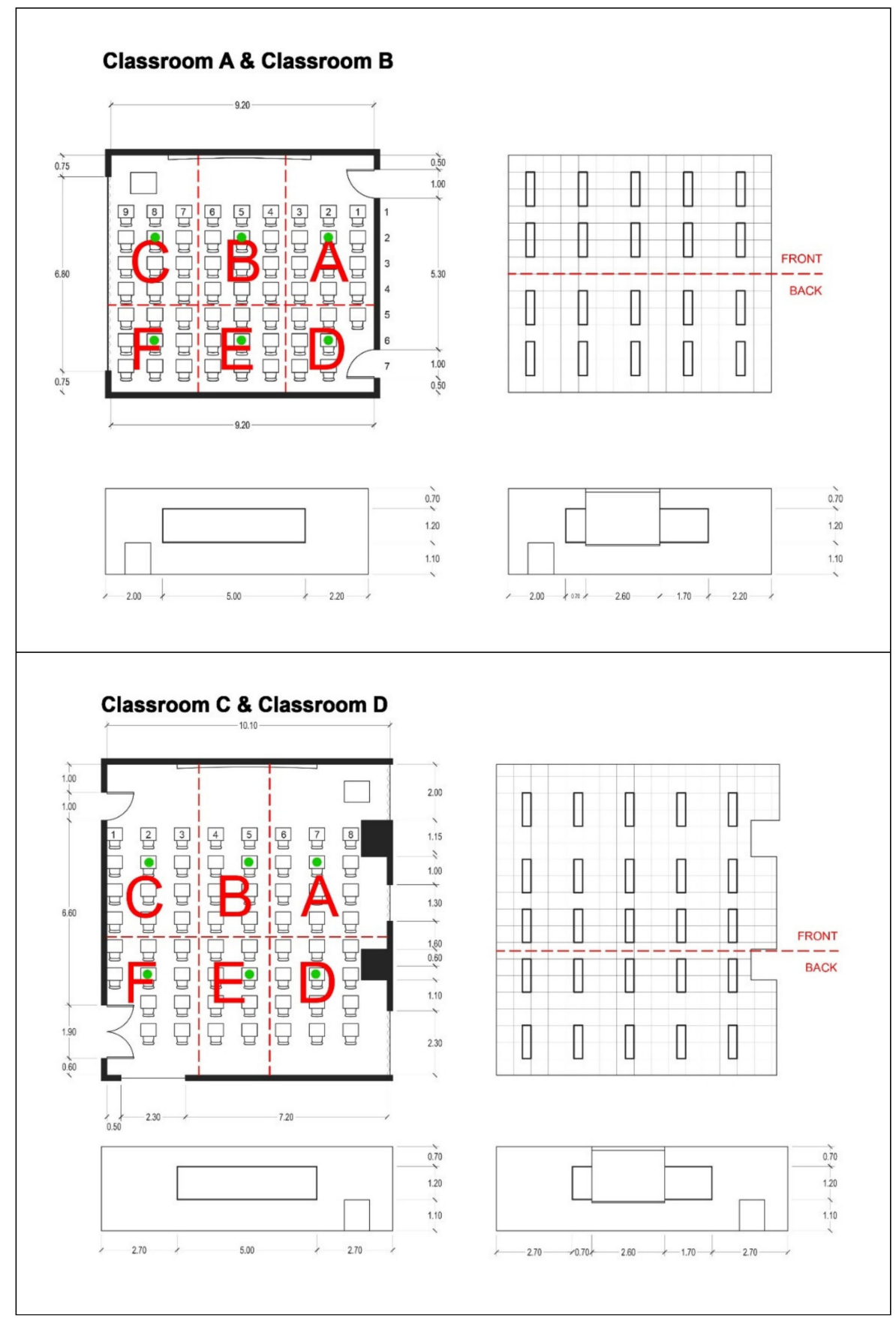

Figure 2. Classroom plan (UL), reflected ceiling plan with two light zones (UR), front elevation without projector screen (BL), front elevation with projector screen (BR). 
Table 1. Layout plan, condition and seating section for each classroom.

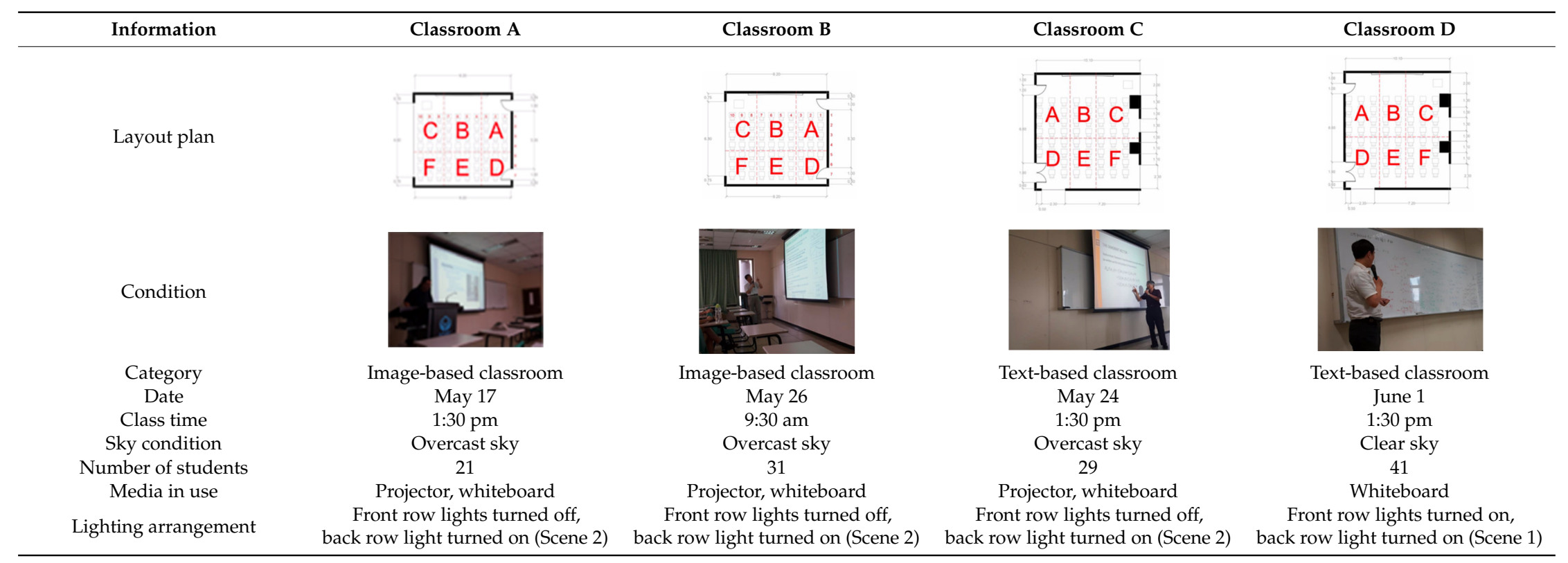


Table 2. Layout plan, condition and seating section for each classroom.

\begin{tabular}{ccc}
\hline Surface & Estimated Reflectance & Color and Other Properties \\
\hline Whiteboard & 0.75 & White, glossy \\
Projector screen & 0.75 & Light Grey, matt, retractable \\
Student's desk & 0.60 & White, matt \\
Curtain & 0.50 & Greenish, matt, folded, retractable \\
Wall & 0.75 & Light yellow, matt \\
Ceiling & 0.70 & White, matt, acoustic panel \\
Floor & 0.30 & Dark yellow, slightly glossy \\
\hline
\end{tabular}

For data analysis, the classroom seating was divided into different sections because classroom users will have different fields of view and different experiences of the classroom depending on their position in the room. The division was determined by splitting the seating arrangement in an equal manner between the front and back rows and among the door side, middle, and window side. The seating sections and their corresponding labels were as follows: front row-door side (A), front row-middle (B), front row-window side (C), back row-door side (D), back row-middle (E), and back row-window side $(\mathrm{F})$, as shown in Table 1.

The last two rows of Table 1 are the records of the lighting arrangement and of the media in use (projector and/or whiteboard) during the class. In general, the lecturer chose how to achieve the optimal lighting condition that the classroom could provide. Notably, the window curtains were never retracted; thus, daylight was never a factor in the overall indoor lighting condition.

Figure 2 details the key plans and elevation of the classrooms. All classrooms have two lighting zones (front and back) with on-off control. Green dots were the locations where the HDRi measurements took place. The lighting fixture is made of a $120 \mathrm{~cm} \times 30 \mathrm{~cm}$ glossy aluminum casing with two $28 \mathrm{~W}$ T5 865 fluorescent light tubes, running perpendicular to the whiteboard. Table 2 lists the estimated reflectance of the surface material in the classroom based on the grey card contrast method [16]. Color and other properties were determined by visual inspection.

\subsection{Questionnaire Survey}

To determine how the users actually felt and performed inside the classroom, visual comfort questionnaires were designed. The questionnaires consisted of four sections: physiological symptoms, visual annoyance and task performance, user preference, and general conclusion. Students received oral instructions and the questionnaires from one of the authors before the class began, completed it during the class and returned it to the surveyor one hour into the class session or during the class break (whichever came first).

The questionnaires were designed in English. Since most of the respondents used Mandarin Chinese as their primary language, Chinese translations were added next to every question. Returned questionnaires were manually sorted to separate valid and invalid questionnaires. Questionnaire responses were processed using Microsoft Excel, which produced graphs and charts to illustrate the survey results.

\subsubsection{Physiological Symptoms}

Part A of the survey asks about the physiological indications that may occur to the users. It consists of six "yes or no" questions (Figure 3). The six symptoms described in the question are dry eyes, heavy eyes, strained and sore eyes, slight headache, continuous blinking, and a dazzled feeling. They were designed as separate questions so that the respondents had more than one to answer during the questionnaire survey. 
PART A - PHYSIOLOGICAL SYMPTOMS 生理狀況

Please pick an answer (yes/no) according to how you physically feel during the whole lecture 請根據自己在課堂中的生理狀況選擇是或否

1. My eyes feel dry 我的眼睛感覺乾燥

$\square$ Yes 是 $\quad \square$ No 不是

2. My eyes feel heavy 我的眼睛有點睜不開

$\square$ Yes 是 $\square$ No 不是

3. I feel a strain and sore in my eyes 我威覺眼周很緊、眼睛很酸

$\square$ Yes 是 $\square$ No 不是

4. I feel a slight headache 我感覺有輕微頭痛

$\square$ Yes 是 $\square$ No 不是

5. I tend to blink a lot 我會一直想眨眼

$\square$ Yes 是 $\quad \square$ No 不是

6. I feel dazzled 我感覺有點目眩 (眼花)

$\square$ Yes 是 $\square$ No 不是

Figure 3. Question set for physiological symptoms.

The intention for this section was to determine how many people experienced at least one physical symptom during lecture sessions. Furthermore, it is also necessary to know which of the six symptoms was most common. The result from this section was compared to the user's general opinion of the visual comfort level to help verify whether physiological symptoms are associated with feelings of discomfort.

\subsubsection{Visual Annoyance and Task Performance}

Part B of the survey asks about how users perform and what kind of disturbances they may feel during lecture sessions. It consists of 11 questions divided into five different groups: reading on the desk, writing on the desk, receiving information through the whiteboard, receiving information through the projector, and task switching (Figure 4). The grouping reflects that classroom users need to constantly focus on three working surfaces. Respondents answer the question with a number between -3 (lowest satisfaction) and 3 (highest satisfaction).

The intention of this section was to determine how users perform in learning-related tasks in the classroom. In this section, which used a scale between -3 and 3 , mean values were calculated for each question to determine the answer's average score. A mean value closer to 3 means that subjects find it comfortable, and a mean value closer to -3 means that subjects find it uncomfortable. Respondents completed the questionnaire in real time based on how they actually perceived the luminous environment during the lecture session. Semantic differential (SD) graph was utilized to present the results for all four classrooms. The results were compared to determine which task, lecture content, and classroom setting was more visually demanding. 


\begin{tabular}{|c|c|c|c|c|c|c|c|c|c|}
\hline \multirow{2}{*}{ No } & \multirow{2}{*}{ Statement } & \multicolumn{7}{|c|}{ Voting Scale } & \multirow{2}{*}{ Statement } \\
\hline & & -3 & -2 & -1 & 0 & 1 & 2 & 3 & \\
\hline \multicolumn{10}{|c|}{ READING ON DESK 在桌子上閱讀 } \\
\hline 1 & $\begin{array}{l}\text { Unable to read the on-desk } \\
\text { content } \\
\text { 我無法閱讀桌上的文字 }\end{array}$ & & & & & & & & $\begin{array}{l}\text { Able to read the on-desk content } \\
\text { clearly } \\
\text { 我能夠清楚閱讀桌上的文字 }\end{array}$ \\
\hline 2 & $\begin{array}{l}\text { Reading causes discomfort to the } \\
\text { eye } \\
\text { 閱讀會讓我的眼睛不舒服 }\end{array}$ & & & & & & & & $\begin{array}{l}\text { Reading takes no effort } \\
\text { 對我來說閱讀一點也不費力 }\end{array}$ \\
\hline
\end{tabular}

\begin{tabular}{|c|c|c|c|c|c|c|c|c|c|}
\hline \multicolumn{10}{|c|}{ WRITING ON DESK 在桌子上寫字 } \\
\hline \multirow{2}{*}{3} & \multirow{2}{*}{$\begin{array}{l}\text { Writing makes me } \\
\text { uncomfortable } \\
\text { 我無法舒服的寫字 }\end{array}$} & -3 & -2 & -1 & 0 & 1 & 2 & 3 & I can write comfortably \\
\hline & & & & & & & & & 我可以很自在地寫字 \\
\hline 4 & $\begin{array}{l}\text { The text I'm writing looks blurry } \\
\text { 我寫的字看起來糊糊的 }\end{array}$ & & & & & & & & $\begin{array}{l}\text { The text I'm writing looks very clear } \\
\text { 我寫的字看起來很清楚 }\end{array}$ \\
\hline \multicolumn{10}{|c|}{$\begin{array}{l}\text { SEEING DISPLAYED INFORMATION (PROJECTOR) 看投影布幕上影示的資訊 } \\
* \text { * }\end{array}$} \\
\hline 5 & $\begin{array}{l}\text { Feel distracted when looking at } \\
\text { the projector } \\
\text { 看螢幕會讓我分心 }\end{array}$ & & & & & & & & $\begin{array}{l}\text { Feel no distraction at all } \\
\text { 看螢幕不會讓我分心 }\end{array}$ \\
\hline 6 & $\begin{array}{l}\text { Feel that the screen causes glare } \\
\text { to the eye } \\
\text { 照射在螢幕上的強光會讓我部 } \\
\text { 分看不見 }\end{array}$ & & & & & & & & $\begin{array}{l}\text { Feel no glare at all } \\
\text { 螢幕上沒有刺眼的強光 }\end{array}$ \\
\hline 7 & $\begin{array}{l}\text { Unable to see text and numbers } \\
\text { 我看不見螢幕上顥示的資訊 }\end{array}$ & & & & & & & & $\begin{array}{l}\text { Able to see displayed content clearly } \\
\text { 我能夠清楚看見螢幕上顯示的資訊 }\end{array}$ \\
\hline \multicolumn{10}{|c|}{$\begin{array}{l}\text { SEEING DISPLAYED INFORMATION (WHITEBOARD) 看白板上顯示的資訊 } \\
\text { *note: if your class doesn't use whiteboard, skip this part!*如果您的課堂沒有使用白板, 請略過此部分* }\end{array}$} \\
\hline 8 & $\begin{array}{l}\text { Feel distracted when looking at } \\
\text { the screen } \\
\text { 看白板會讓我分心 }\end{array}$ & & & & & & & & $\begin{array}{l}\text { Feel no distraction at all } \\
\text { 看螢幕不會讓我分心 }\end{array}$ \\
\hline 9 & $\begin{array}{l}\text { Feel that the whiteboard causes } \\
\text { glare to the eye } \\
\text { 照射在白板上的強光會造成部 } \\
\text { 分看不見 }\end{array}$ & & & & & & & & $\begin{array}{l}\text { Feel no glare at all } \\
\text { 螢幕上沒有刺眼的強光 }\end{array}$ \\
\hline 10 & $\begin{array}{l}\text { Unable to see text and numbers } \\
\text { 我看不見白板上顯示的資訊 }\end{array}$ & & & & & & & & $\begin{array}{l}\text { Able to see displayed content clearly } \\
\text { 我能夠清楚看到白板上顯示的資訊 }\end{array}$ \\
\hline \multicolumn{10}{|c|}{ TASK SWITCHING 轉移目光焦點 } \\
\hline 11 & $\begin{array}{l}\text { Switching between task causes } \\
\text { my eyes to work hard } \\
\text { 將目光從桌子上轉移到螢幕 } \\
\text { 上, 我的眼睛會需要一些時間 } \\
\text { 適應 }\end{array}$ & & & & & & & & $\begin{array}{l}\text { I can switch between task with no } \\
\text { effort } \\
\text { 我可以很自在地轉移目光焦點 }\end{array}$ \\
\hline
\end{tabular}

Figure 4. Question set for visual annoyance and task performance.

\subsubsection{User Preference}

Part $C$ of the survey asks about how the user feels about the setting of the classroom's lighting; furthermore, this part asks what they would do if they were given the opportunity to change something in the classroom. It consists of four questions: room brightness, room lighting temperature, projector brightness, and curtain setting (Figure 5). The intention of this section was to determine the user's opinion about the classroom's setting, identify what needs to be improved and develop a plan to make the improvement. The respondents choose only one answer for each question. The results showed how the users actually perceived the space and how they thought the curtain should be arranged to achieve better visual comfort. 


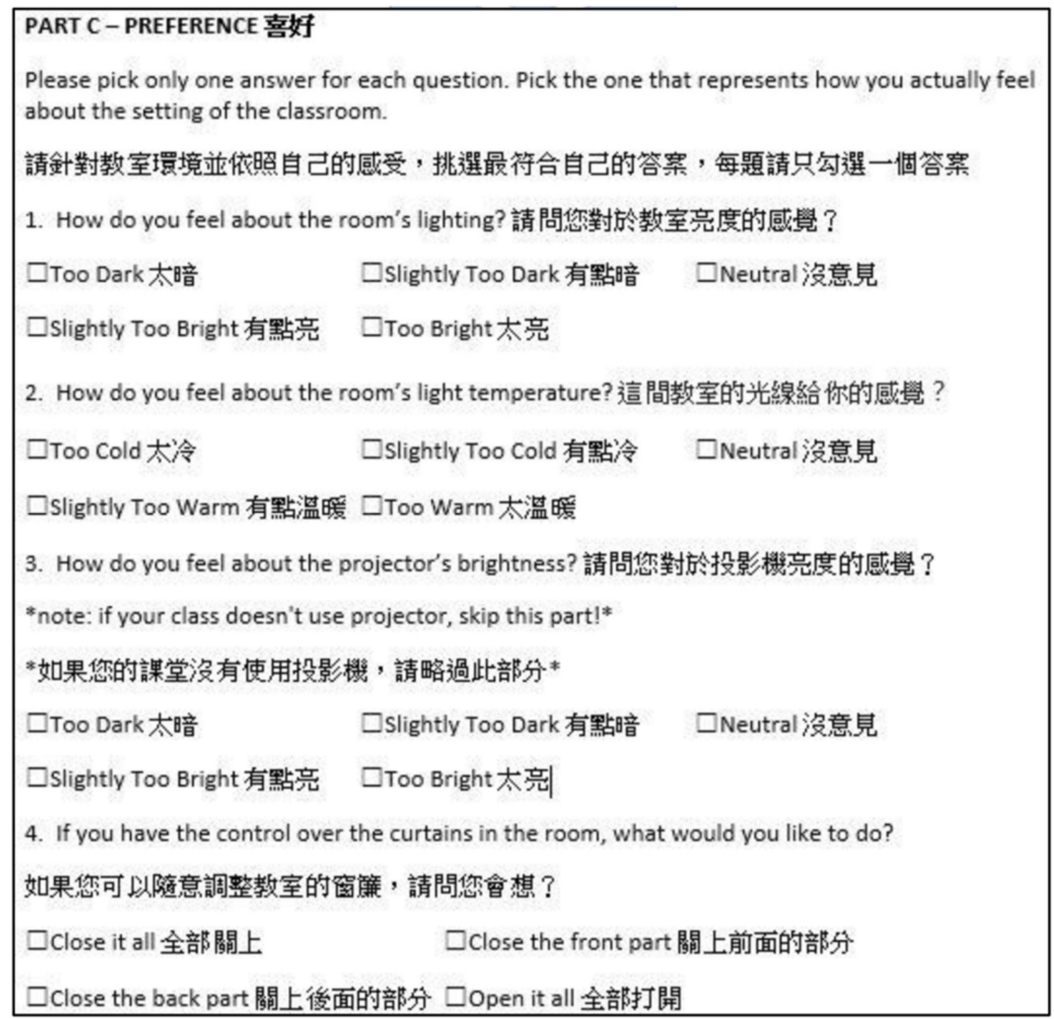

Figure 5. Question set for user preference.

\subsubsection{General Conclusion}

Part D of the survey asks about the user's general judgment of visual comfort in the classroom. The questions are listed in Figure 6. The intention of this section was to determine the user's general comfort level when utilizing the space. A simple choice between comfortable/uncomfortable was used. Moreover, the main parameters that cause discomfort were also asked, and the respondents could pick more than one answer. All questionnaire results were processed using Microsoft Excel, which produced graphs and charts to illustrate the questionnaire results.

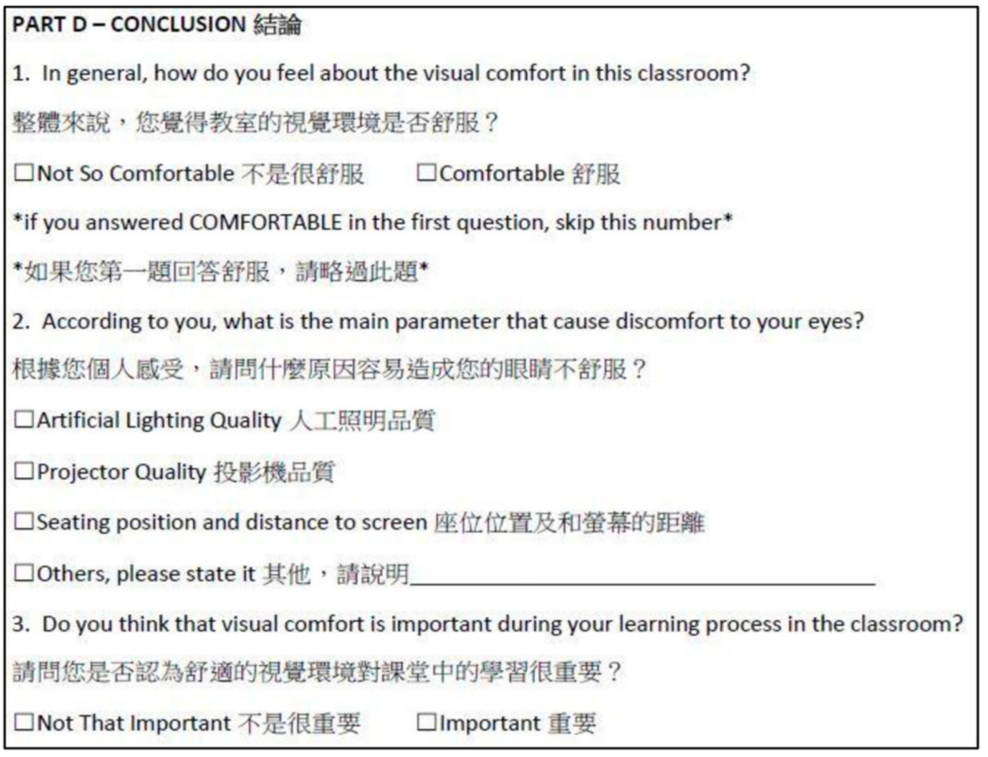

Figure 6. Question set for general conclusion. 


\subsection{Field Measurements and Data Processing}

Field measurements were conducted in 2016 during the second week of May to the first week of June, in the TR Building of the NTUST. In all classrooms, projector screens were measured with the full white image and curtains were fully unfolded to block the daylight as observed in actual class sessions. More than 600 photos were taken and assembled into 48 HDRi images. HDRi photography was carried out 45 to $60 \mathrm{~min}$ before the class so that it would not disturb the lecture session. Luminance mapping was performed using the HDR imaging technique. The HDR images were used to map the spatial luminance distribution. The following equipment and instruments were used in the field measurements: 1. DSLR Camera (Canon 7D), 2. Fisheye lens (Sigma Circular Fisheye lens $4.5 \mathrm{~mm}$ f/2.8 180 degrees), 3. Luminance meter (Konica Minolta LS-110), 4. Illuminance meter (Dr. Meter LX1330B), and 5. Tripod (Figure 7).

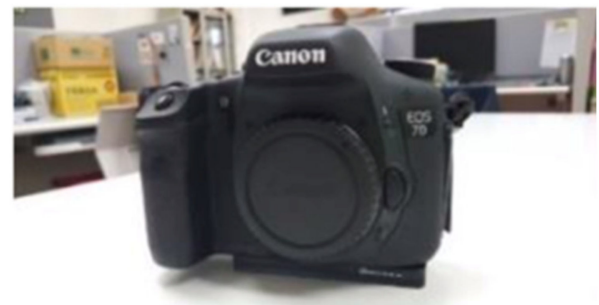

(a)

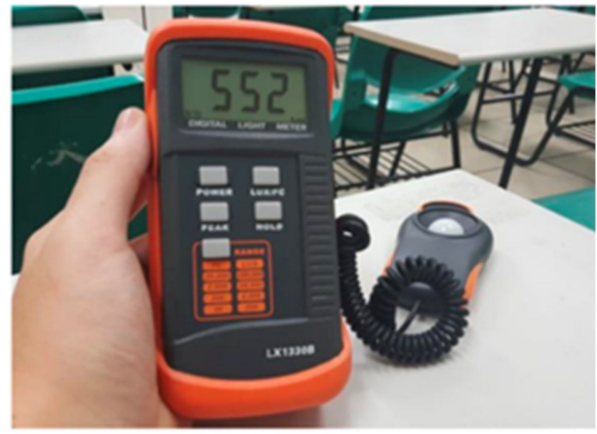

(d)

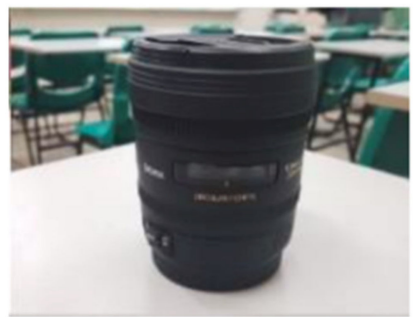

(b)

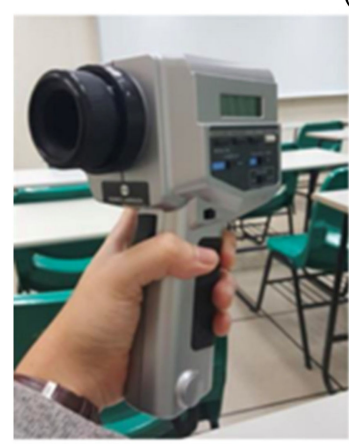

(e)

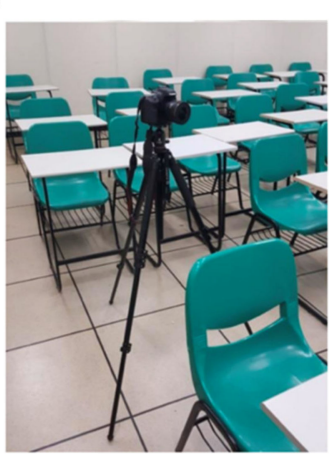

(f)

Figure 7. Experiment tools for HDR capture (a) Canon 7D DSLR camera; (b) Sigma fisheye lens 4.5 mm; (c) Dr. Meter LX1330B illuminance meter; (d) Konica Minolta LS-110 Luminance meter; (e) Final assembly of camera, lens, and tripod.

The overexposure was bright enough and the underexposure was dark enough to optimize the multiple exposure image capturing process. The Canon 7D camera and the Sigma fisheye lens were set as shown in Table 3. The f-stop was set at $\mathrm{f} / 6.3$ so that the resulting image would not produce blurry areas, while the ISO setting and shutter speed range were determined through preliminary testing in classroom conditions. A tripod was used during image capture to prevent the camera from shaking, which would result in blurred images during the HDRi assembly. The camera was positioned at the eye level of a seated student, which was approximately $1.2 \mathrm{~m}$ from the floor. It was then placed behind a target desk and adjusted so that both the horizontal work plane and vertical work plane were visible in the field of view.

Table 3. Experiment setup for HDR capture.

\begin{tabular}{cccccccc}
\hline ISO & f-Stop & $\begin{array}{c}\text { Shutter Speed } \\
\text { Range }\end{array}$ & $\begin{array}{c}\text { Red Eye } \\
\text { Reduction }\end{array}$ & White Balance & Focus & $\begin{array}{c}\text { Picture } \\
\text { Style }\end{array}$ & Metering \\
\hline 800 & $\mathrm{f} / 6.3$ & $\begin{array}{c}\text { Under- to } \\
\text { over-exposure }\end{array}$ & off & $\begin{array}{c}\text { Auto white } \\
\text { balance }\end{array}$ & One-shot AF & Standard & $\begin{array}{c}\text { Evaluate } \\
\text { metering }\end{array}$ \\
\hline
\end{tabular}




\subsubsection{HDR Capture and Field Measurement}

Multiple exposure photographs (Figure 8) were taken from the 6 different sections for each classroom, with two different lighting scenes (Scene 1: all lights on and without a projector; Scene 2: front row lights on, back row lights off, and with a projector), as shown in Figure 9. Classrooms A, $\mathrm{B}$, and $\mathrm{C}$ all employed the second lighting scene (Scene 2), while Classroom D employed the first lighting scene (Scene 1). For each scene, approximately 11 to 15 photos were taken, from complete underexposure (dark) to complete overexposure (bright). Each photo session took approximately 40 to $60 \mathrm{~min}$.

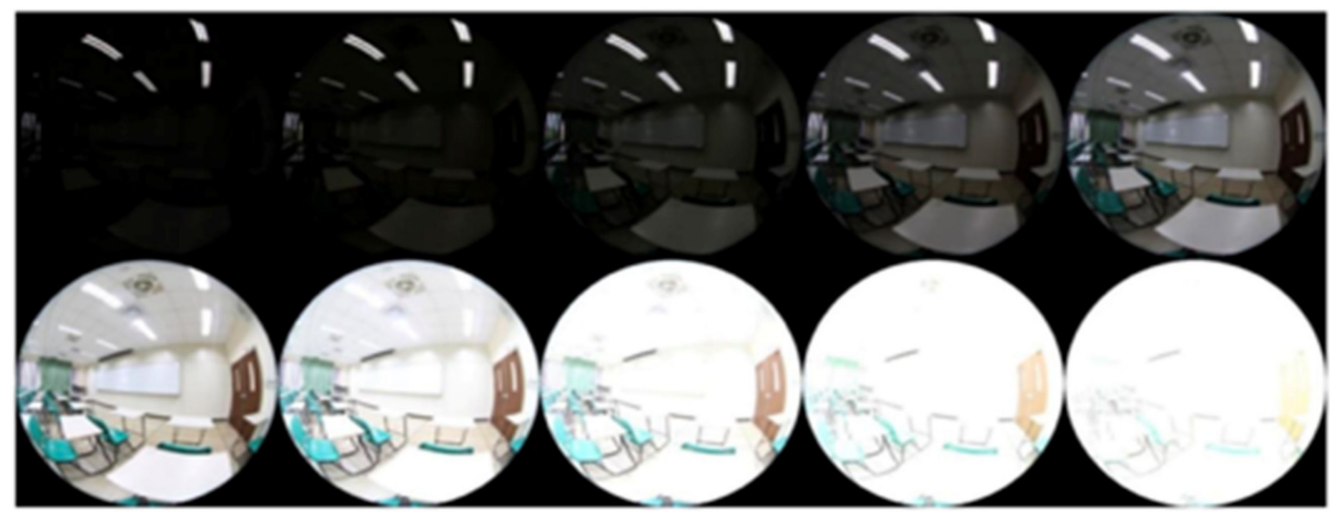

Figure 8. Ten sequential images of classroom A from under-exposure to over- exposure.

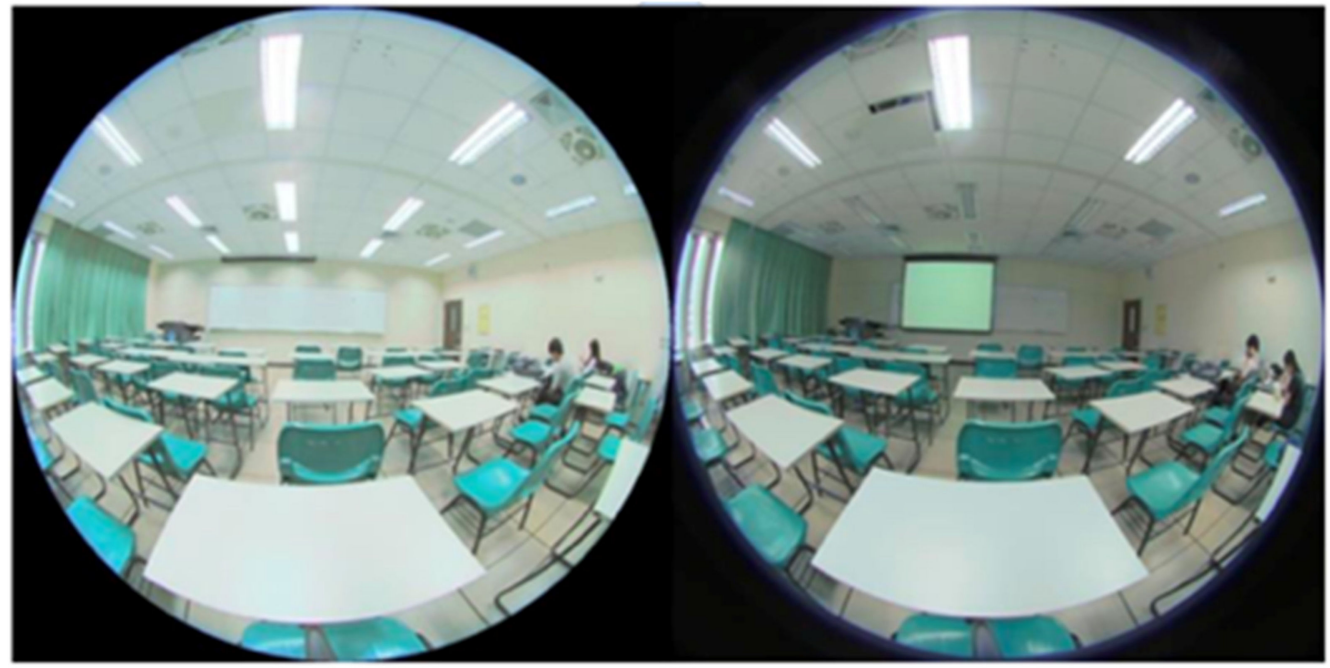

Figure 9. Illustration of Scene 1 with all lights turned on and no projector (left) and Scene 2 with front lights turned off and projector (right).

Regarding the need for luminance mapping validation and HDRi luminance calibration, the following additional measurements were taken: 1. luminance of a designated spot (for calibration), 2. horizontal work plane (desk) illuminance, and 3. vertical illuminance. The designated spot was marked using either paper or yellow tape with a hole in the middle so that the luminance being measured was the actual luminance of the target material (the whiteboard in this case) (Figure 10). The designated target was chosen randomly as long as it was in the whiteboard area and visible from all six views. Horizontal work plane illuminance was measured by placing an illuminance sensor in the middle of a desk in each section. Vertical illuminance was measured by holding an illuminance sensor directly in front of the camera lens while remaining perpendicular to the horizontal work plane. 


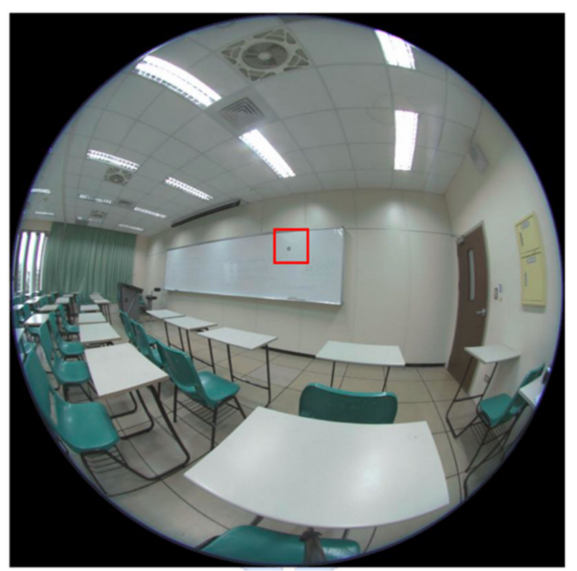

Figure 10. A designated spot for luminance measurement and luminance calibration (marked by the red rectangle).

\subsubsection{HDR Image Compiling and Luminance Calibration}

After all the multiple exposure images were collected, the images were processed using photosphere software (Figure 11). Photosphere is a Mac-based software application to build an HDRi from a sequence of JPEG images that have exactly the same view but different exposure values $[17,18]$. In addition, photosphere software allows the user to perform HDRi corrections such as lens flare removal, ghost removal, image alignment and exposure adjustments. The resulting HDRi has a luminance value embedded in each image pixel. These luminance values are calibrated to match the real luminance distribution in the real scene.

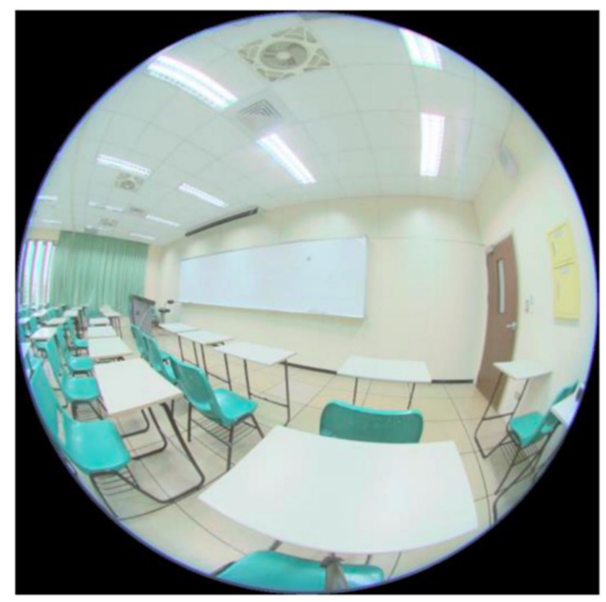

Figure 11. Resulting HDR image of TR-311 that has been tone-mapped generated by photosphere.

Luminance calibration was performed in hdrscope $[19,20]$. Hdrscope is a Windows-based architectural lighting and daylighting analysis software. It applies several Radiance commands as well as 2D-drawing functions [19]. Hdrscope also features commands related to the processing and analysis of HDRis. The features applied in this study included the following: the per-pixel luminance analysis of a single region, false color image conversion, image cropping, image masking, and hemispherical image projection. After calibration, the HDRi was ready to be utilized for lighting analysis.

The per-pixel luminance analysis was conducted with three surfaces: the horizontal work plane (desk), whiteboard, and projection screen (if available). The resulting mean value was organized in a Microsoft Excel spreadsheet for cross comparisons. A false color image conversion was performed to assist in the visual inspection of the abnormality in luminance distribution from the set viewport. A glare analysis was executed by the Evalglare program embedded in hdrscope. 


\subsubsection{Glare Analysis by Evalglare}

The Evalglare program [21] was developed to evaluate visual discomfort from daylight solutions. It can evaluate glare from HDR photographs. The glare index in the Evalglare program calculates the Daylight Glare Probability (DGP), Daylight Glare Index (DGI), Unified Glare Rating (UGR), Visual Comfort Probability (VCP), and CIE Glare Index (CGI). Evalglare has been widely used in industry and research contexts [22,23] because it can calculate accurate discomfort glare indices [24]. In this study, UGR, the designated glare index by CIE, is used to evaluate the interior glare condition, while the DGP is also observed for possible daylight glare conditions.

The Evalglare program also identifies the possible glare sources by coloring them in the HDRi (Figure 12). The possible glare sources have excessive luminance levels in contrast to their surroundings.

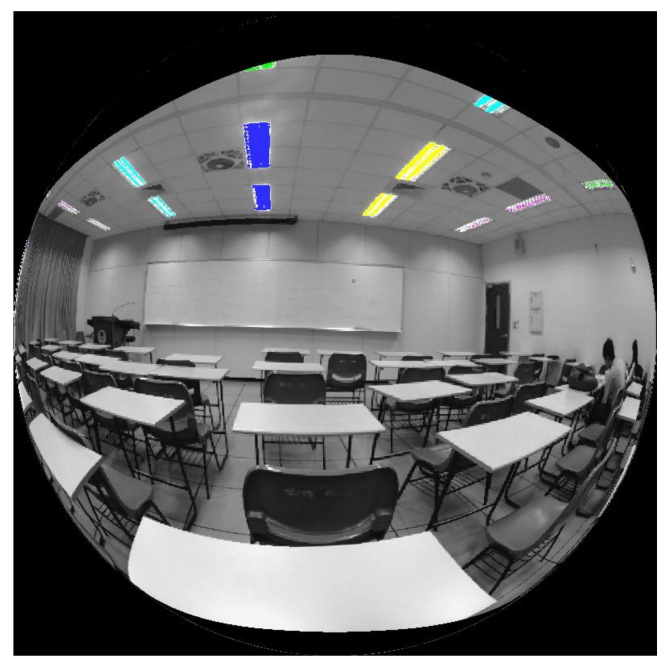

Figure 12. Example of resulting glare analysis image generated by Evalglare. Different colors represent different glare sources.

\section{Results and Discussions}

\subsection{Questionnaire Results}

In the four subject classrooms, 122 questionnaires were collected (Table 4). The number of male respondents was $81(66 \%)$, and the number of female respondents was $41(34 \%)$. The average age of respondents was 19 years old. Data from each section of the questionnaire were processed in Microsoft Excel to create graphs and charts for further comparisons. It should be noted that during any lecture session, only one lighting arrangement (Scene 1 or Scene 2) was used. The lighting arrangement during the lecture session of Classroom D was Scene 1 (front row lights on, back row lights on, projector off). The lighting arrangement during the lecture session of Classrooms A, B, and C was Scene 2 (front row lights off, back row lights on, projector on).

Table 4. Respondent (student) basic data.

\begin{tabular}{ccccc}
\hline \multirow{2}{*}{ Seating Section } & \multicolumn{4}{c}{ n-of Students } \\
\cline { 2 - 5 } & Classroom A & Classroom B & Classroom C & Classroom D \\
\hline A & 5 & 8 & 4 & 5 \\
B & 3 & 6 & 2 & 8 \\
C & 2 & 3 & 5 & 7 \\
D & 2 & 6 & 9 & 4 \\
E & 5 & 7 & 5 & 9 \\
F & 4 & 1 & 4 & 8 \\
Total each room & 21 & 31 & 29 & \\
Total & & & & \\
\hline
\end{tabular}




\subsubsection{Physical Symptoms (Part A)}

The results from Part A in the questionnaire are shown in Figure 13. Since physical symptoms may vary from one individual to another, the calculation was based on people feeling at least one physical symptom. The total number of each physical symptom encountered was also calculated to determine which physical symptoms were more frequent. The percentages of respondents who experienced at least one physical symptom (Part A) during lectures in Classrooms A to D were 71\%, 77\%, 62\%, and $66 \%$, respectively (Figure 13). The most common symptom across all respondents was eyestrain $(33 \%)$, followed by constant blinking $(25 \%)$, dry eyes $(15 \%)$, headache $(11 \%)$, and heavy eyes $(10 \%)$. Only $5 \%$ of respondents felt dazzled while using the space. The findings are highly agreeable with a recent European Visual Display Terminal (VDT) study [15]. Both studies showed high percentage of respondents with vision relative physical symptoms. It is worth noting that the duration of a class session is much shorter than the duration of the VDT usage in the European study.

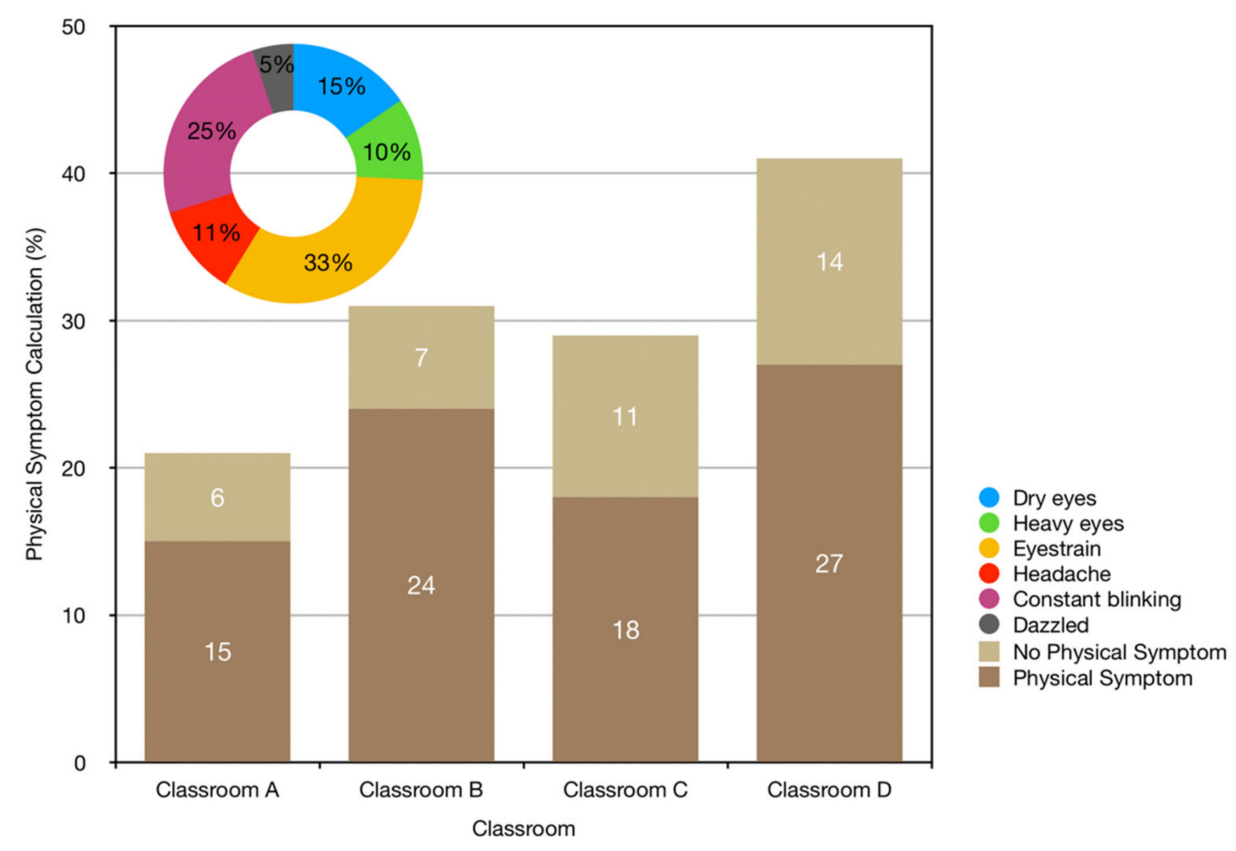

Figure 13. Overall comfort level feedback from user (questionnaire Part A).

\subsubsection{Task Performance and Visual Annoyance (Part B)}

The next discussion assesses Part B in the questionnaire (Figure 4). A list of questions and their grouping can be seen in Figure 14. The five question groups included the following: reading on the desk (color coded orange), writing on the desk (color coded green), seeing the projection screen (color coded blue), seeing the whiteboard (color coded yellow), and task switching (color coded gray). Mean value analysis was employed to determine which task could be performed more comfortably than the others. The mean value was calculated per question rather than per question group. The mean values were calculated for each subject classroom rather than as a whole. The resulting mean value can be seen in Figure 15. Mean values range from -3 to 3, where -3 resembles the most negative result (discomfort/unable to do task), while 3 resembles the most positive result (comfort/able to do task). Subject $\mathrm{D}$ did not have any mean value for questions 5,6 , and 7 because the projector was not used during the lecture session (Scene 1). 


\begin{tabular}{|c|c|c|c|}
\hline \multirow[b]{2}{*}{$\begin{array}{l}\text { Question } \\
\text { Number }\end{array}$} & \multirow[b]{2}{*}{ Question Group } & \multicolumn{2}{|c|}{ Statements } \\
\hline & & $\begin{array}{l}\text { Most Negative Statements } \\
(-3)\end{array}$ & $\begin{array}{l}\text { Most Positive Statements } \\
\text { (3) }\end{array}$ \\
\hline 1 & \multirow{2}{*}{ Reading on desk } & $\begin{array}{l}\text { Unable to read on desk } \\
\text { content }\end{array}$ & Able to read clearly \\
\hline 2 & & $\begin{array}{l}\text { Reading causes discomfort } \\
\text { to the eye }\end{array}$ & Reading takes no effort \\
\hline 3 & \multirow{2}{*}{ Writing on desk } & Writing causes discomfort & Able to write comfortably \\
\hline 4 & & Writing look blurry & Writing takes no problem \\
\hline 5 & \multirow{3}{*}{$\begin{array}{l}\text { Seeing projector } \\
\text { screen }\end{array}$} & Distracted when looking & No distraction \\
\hline 6 & & Screen causes glare & No glare at all \\
\hline 7 & & Unable to see content & Able to see content \\
\hline 8 & \multirow{3}{*}{$\begin{array}{l}\text { Seeing white } \\
\text { board }\end{array}$} & Distracted when looking & No distraction \\
\hline 9 & & Whiteboard causes glare & No glare at all \\
\hline 10 & & Unable to see content & Able to see content \\
\hline 11 & Task switching & $\begin{array}{l}\text { Switching task causing eyes } \\
\text { to work hard }\end{array}$ & $\begin{array}{l}\text { Switching task takes no } \\
\text { effort }\end{array}$ \\
\hline
\end{tabular}

Figure 14. List of questions and statement of all experiment subjects from questionnaire Part B.

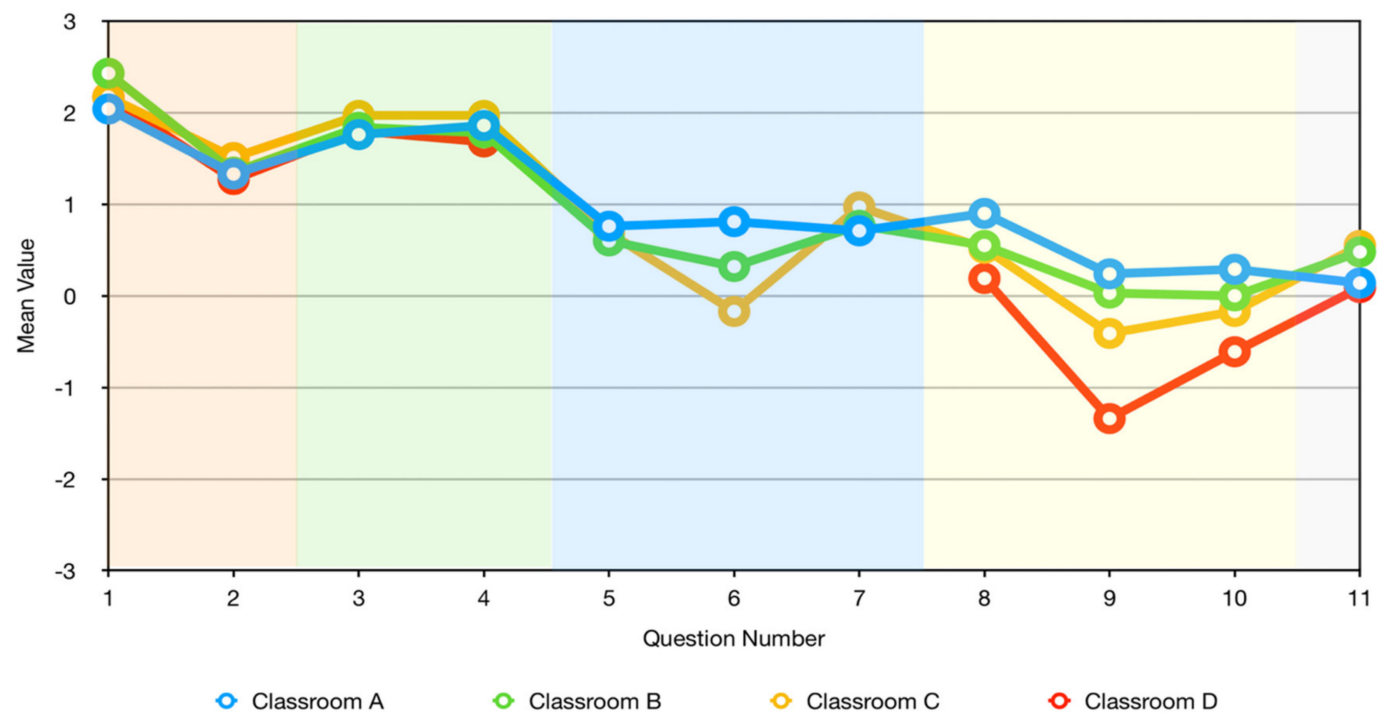

Figure 15. Mean value results for Classrooms A, B, C, and D from questionnaire Part B.

In Classroom A (Scene 2), the two highest mean values were for question 1 (2.04) and question 4 (1.86), which were being able to read on the desk clearly and being able to write on the desk clearly. The lowest mean value was for question $11(0.14)$ and question $9(0.24)$, which were eye discomfort from task switching and glare on the whiteboard (Figure 15). For Classroom B (Scene 2), the two highest mean values were for question 1 (2.42) and question 3 (1.84), which were being able to read on the desk clearly and being able to write comfortably. The lowest mean value was for question $10(0)$ and question $9(0.03)$, which were unable to see the whiteboard content and glare on the whiteboard (Figure 15). For Classroom C (Scene 2), the two highest mean values were for question 1 (2.17) and questions 3 and 4 (both are equal at 1.97), which were being able to read on the desk clearly, being able to write comfortably, and being able to write on the desk clearly. The lowest mean value was for question $9(-0.41)$ and questions 6 and 10 (both are -0.17), which included glare on the whiteboard, glare on the screen, and inability to see the whiteboard content (Figure 15).

In Classroom D (Scene 1), the two highest mean values were for question 1 (2.17) and question 3 (1.8), which were being able to read on the desk clearly and being able to write comfortably. The lowest mean value was for question $9(-1.34)$ and question $10(-0.61)$, which included glare on the whiteboard and inability to see the whiteboard content (Figure 15). The mean value for the first two question 
groups, which covered the desk-based task (reading and writing), was the highest among all with 1.8. The mean value for the third and fourth question groups, which covered the vertical surface-based task (whiteboard and projector), was the lowest, only 0.27. The mean value for task switching was 0.315 .

Overall, tasks on the student's desk surface had the highest score. Text-based teaching classrooms (Classrooms C and D) had glare problems on vertical surfaces, and the glare issue on the whiteboard was especially severe.

\subsubsection{Preferences and Opinions (Part C)}

Part $C$ in the questionnaire asks about user preferences and opinions. It covers the main causes of visual discomfort in the respondents. According to the respondents who picked "uncomfortable" in the overall visual comfort (in Part D of the questionnaire), the most picked main cause of discomfort was artificial lighting quality (49\%), followed by projector brightness (35\%). Only $14 \%$ of respondents picked seating position and distance to screen. The four main causes of discomfort are discussed below.

The overall lighting level chart (Figure 16a) explains how students responded to the lighting condition inside the class. While the most picked answer for all subjects was "neutral", it can be seen from Figure 16a that compared to those in Classroom D, who tended to pick "slightly too bright", respondents from Classrooms A, B, and C tended to pick "slightly too dark". This reflects the effect of the different lighting arrangements between Scene 1 and Scene 2. Users tended to feel that the light level was not adequate in Scene 2 (Classrooms A, B, and C), but felt that the light level was excessive in Scene 2 (Classroom D).

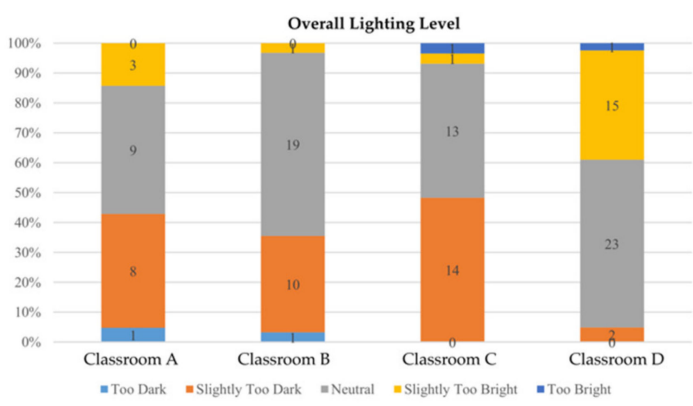

(a)

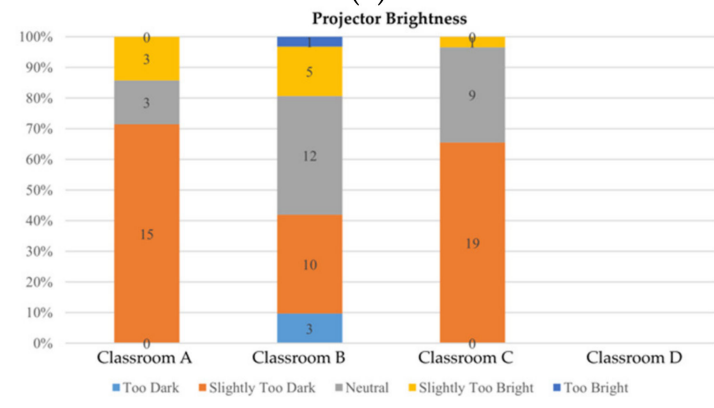

(c)

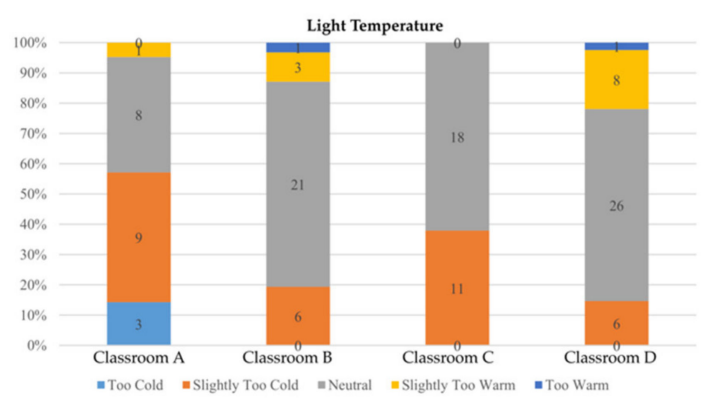

(b)

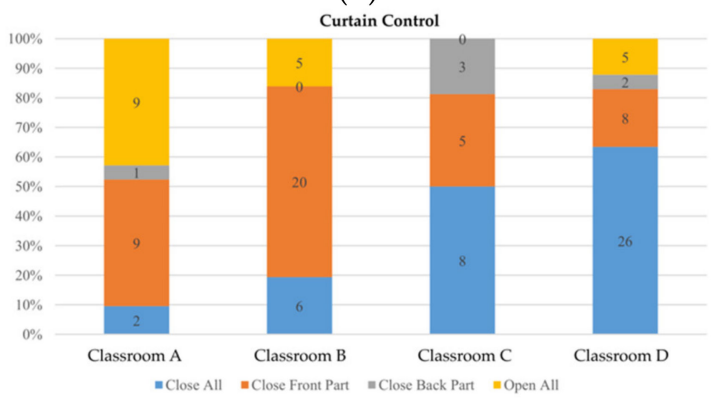

(d)

Figure 16. User opinion graph of the overall lighting level (a), light temperature (b), projector brightness (c), and curtain control (d).

Regarding light temperature (Figure 16b), the most picked answer from respondents in Classroom A was "slightly too cold", while the most picked answer in the other three classrooms was "neutral". There is no distinguishable pattern of preference in the answers.

Regarding the visual comfort in projector brightness (Figure 16c), Classroom D was excluded because it did not use the projector during the lecture. As seen from the graph, respondents in all subject classrooms tended to pick "slightly too dark", which indicates that the current projector brightness may not be at an adequate level. 
Curtains play a role in controlling daylight and daylight glare in the classroom. From the responses to the questionnaire (Figure 16d), respondents in Classroom A and Classroom B preferred to close the front part of the curtain, and those in Classrooms $C$ and $D$ preferred to close the entire curtain. It shows the difficulty in utilizing daylight for classroom lighting with current windows/curtain design.

\subsubsection{Overall Comfort Level (Part D)}

The overall comfort level is related to Part D in the questionnaire (Figure 6). Students were asked about their general judgment of visual comfort in the classrooms. There were only two available answers, "comfortable" and "uncomfortable". The percentages of people feeling comfortable in Classrooms A to D were $43 \%, 55 \%, 55 \%$, and $73 \%$, respectively (Figure 17). Overall, higher portions of students were uncomfortable in the lecture session with a combination of teaching tools (projector and whiteboard) than in the session with a single tool (whiteboard in Classroom D). In addition, in Classrooms A, B, and C, a higher portion of students sitting in the back row (BR) felt comfortable with the classroom lighting condition than those siting in the front row (FR), whereas in Classroom D, the difference in visual comfort between students in the front and back rows is much less significant.

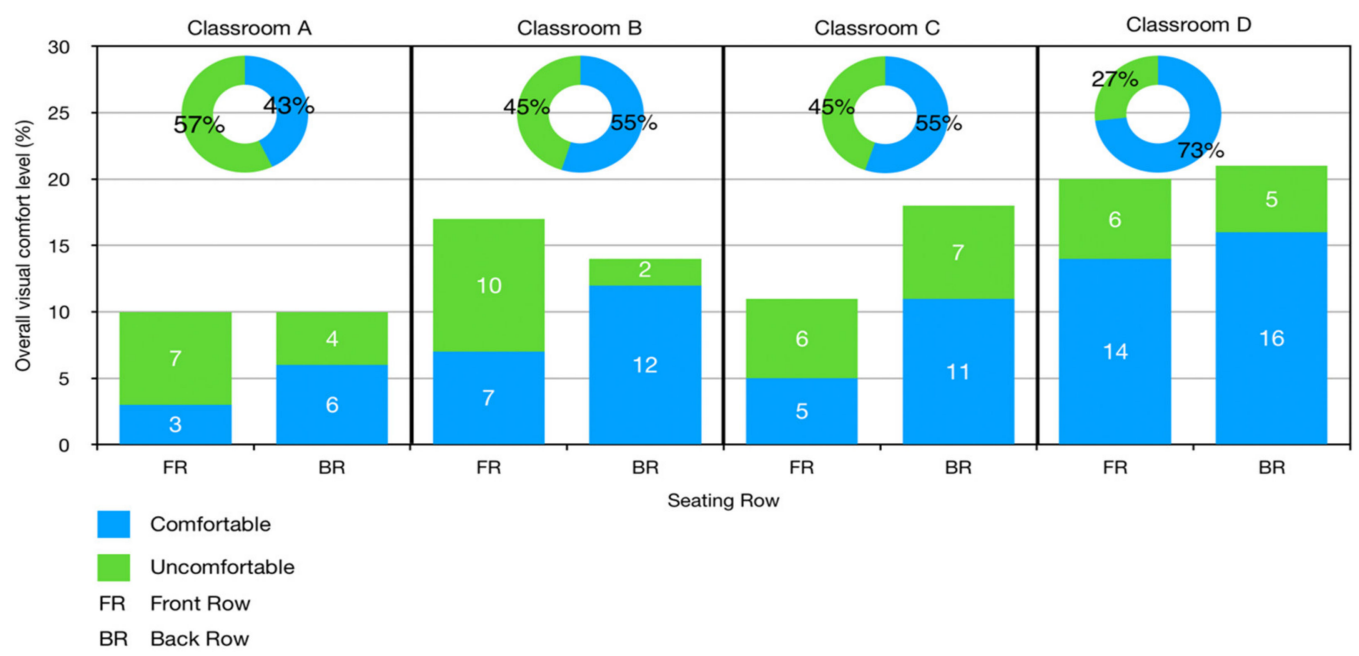

Figure 17. Overall comfort level feedback from user (questionnaire Part D).

\subsection{Field Measurement Result}

Field measurements were carried out to acquire three values from each subject classroom in each seating section: desk illuminance, target point luminance, and vertical illuminance. Field measurements were conducted immediately before the lecture sessions under both lighting arrangement scenes. Table 5 shows that the average desk illuminance in lux (DI) for Scene 1 was 776 lux. The average DI for Scene 2 was 382 lux. There was a major difference in the DI of Scene 2 between the front sections (A-B-C) and the back sections (D-E-F) because artificial lighting for the front part of the class was turned off in Scene 2. Turning off some parts of artificial lighting is a common practice in NTUST classrooms that use projectors. The intention behind this strategy is to reduce the luminance in the area around the projector to create contrast so that the projection screen may seem brighter and clearer. The consequence of using this strategy is that the DI of the FR will be reduced significantly to below 200 lux or, in some cases, even lower than 100 lux. The above results will likely cause visual discomfort for students sitting in the FR of the classroom. Vertical illuminances at the measurement spots ranged from 250 to 440 lux in Scene 1. Thus, it can be derived that the whiteboard illuminance level was always below 500 lux required by the European lighting code [25]. It should be noted that Taiwanese code $[26,27]$ requires the minimal vertical illuminance of 750 lux only for blackboard. 
Table 5. Field measurement results of Classrooms A, B, C, and D for Desk Illuminance (DI).
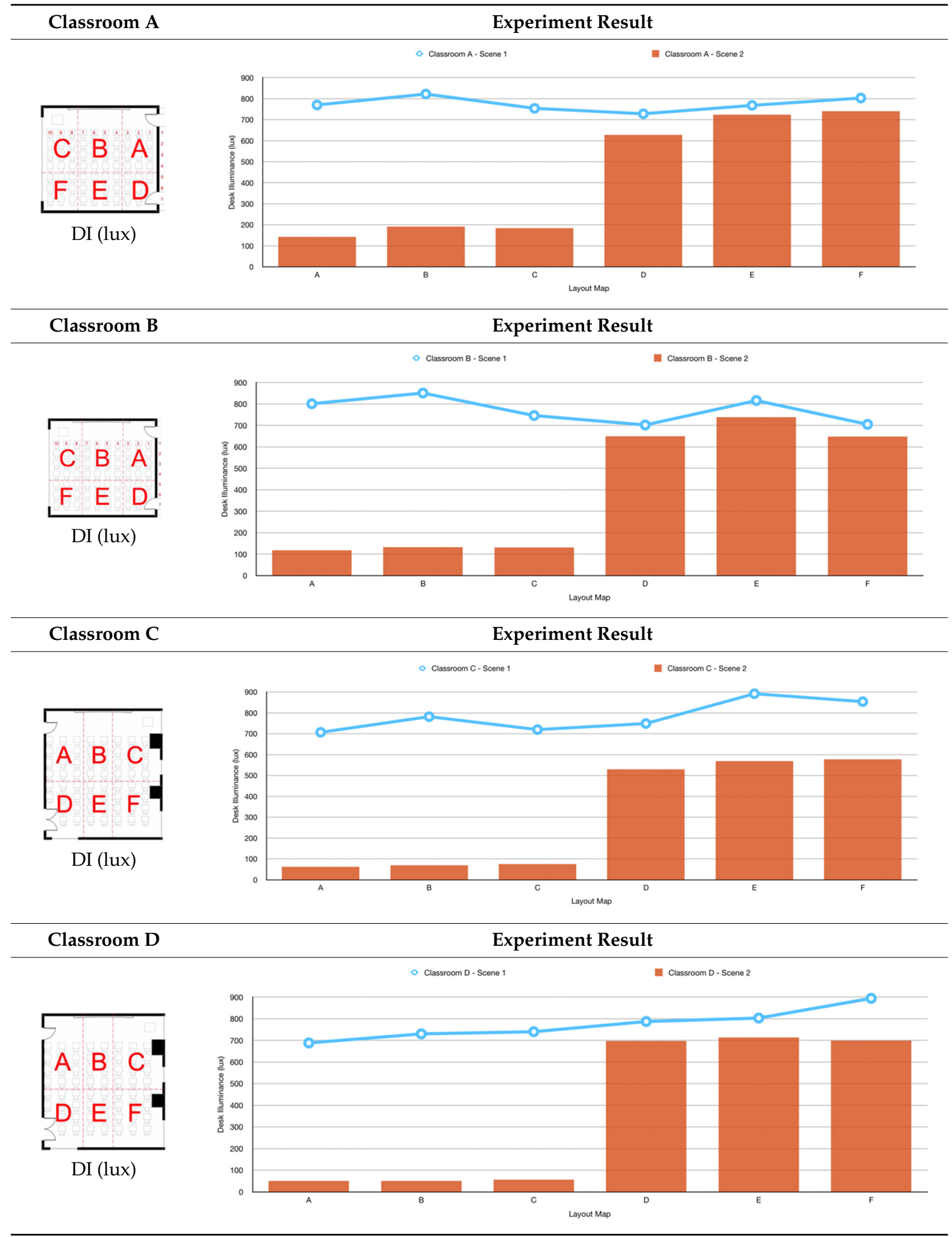

The measurement also showed that in Scene 2, the DI of the BR seating area was slightly reduced compared with that of Scene 1, indicating that the effect of turning off the FR lights can slightly affect the BR as well. However, even with reduced DI, the BR DI of Scene 2 was still above 500 lux, which is the recommended light level for a classroom $[25,26]$. For Scene 1, the DI value ranged between 700 and 900 lux, which is more than $50 \%$ above the recommended light level of 500 lux $[25,26]$. The excessive 
level of desk illuminance in all classrooms in Scene 1 echoes the observations from an earlier UK lighting and discomfort study of 90 classrooms [3]. The phenomenon may be related to the application of the light loss factor or the maintenance factor in lighting design required by lighting codes [25,26].

Classrooms C and D are the same space. However, the field measurements took place at different times and during different lecture sessions. Sky conditions during the field measurements of Classroom $C$ were cloudy and overcast, whereas those for Classroom D were clear and sunny. The differences in DI between these two subject classrooms were relatively low. In Scene 1 (Table 5), the measured DI only slightly varied. However, in Scene 2, the DI for the BR section varied by approximately 100 lux, with Classroom D (clear sky) consistently having a slightly higher number. Upon further investigation (Figure 18), it was found that the desks in the seating area were rearranged between the two field measurements, with Classroom D's desks being closer to the lighting fixtures on the ceiling. The above result indicated that the horizontal lighting level was not homogenous by design. It was also observed that daylight had little effect on the lighting condition in the classroom since the curtains in all classrooms were unfolded to block the daylight when the classes were in session.

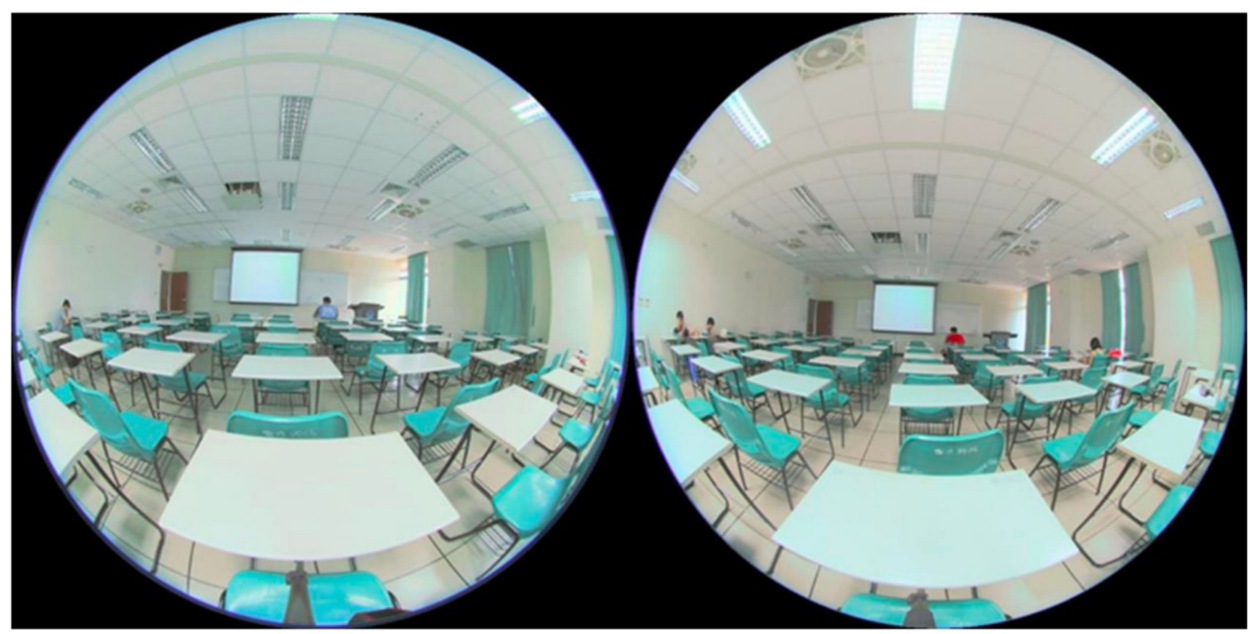

Figure 18. Classroom desk arrangements between two field measurements.

\subsubsection{HDR Photo Results}

Sequential images were merged into HDRis, and a luminance calibration was employed to generate the correct luminance mapping. All of the images were tone-mapped using Reinhart tone mapping. Below are the resulting HDRis, positioned according to the seating sections in each classroom (Figure 19) with two lighting arrangements (Scene 1 and Scene 2). Notably, even though the HDRi photograph was performed in both lighting scenes, the actual lecture sessions could use only one of the two.

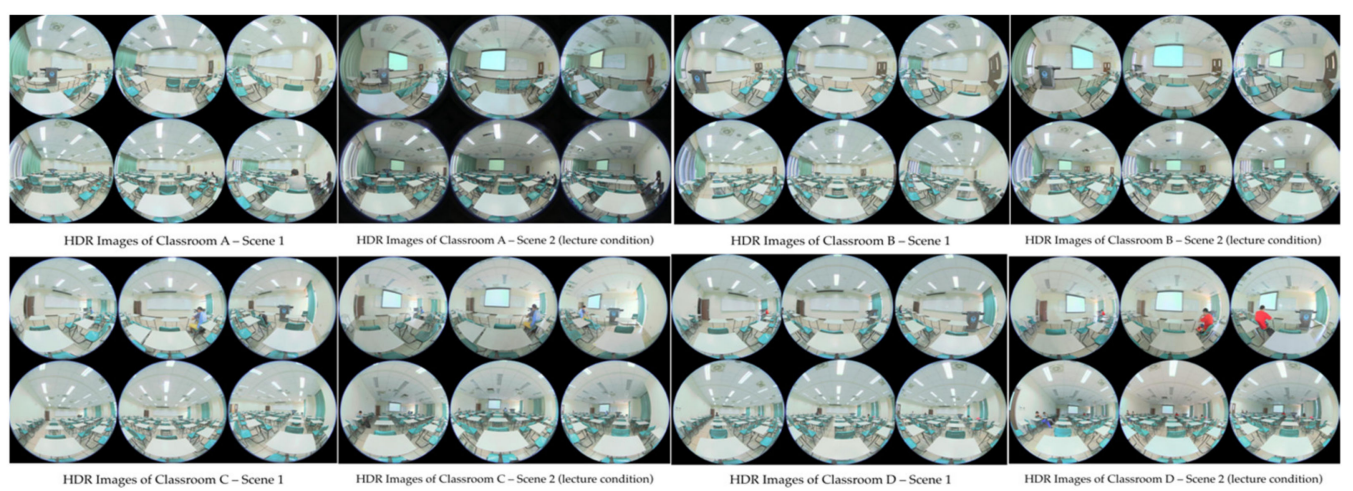

Figure 19. HDRi photo results from 4 classrooms (A, B, C, D) for Scene 1 and Scene 2 (see Appendix A for large images). 


\subsubsection{Viewport Luminance Analysis}

Viewport luminance analysis was carried out with the hdrscope-calibrated HDRis. The focuses were the mean luminance values of the task surfaces. For Scene 1, the values were the desk luminance, whiteboard luminance, and luminance ratio between the desk and the whiteboard. For Scene 2, the values were the desk luminance, whiteboard luminance, projection luminance, and luminance ratio between the above three values.

Viewport Luminance Analysis for Scene 1

As shown in Figure 20, the viewport luminance analysis had a persistent result. In both the classrooms and seating sections, desk luminance was higher than whiteboard luminance. The average ratio between the desk and whiteboard was approximately 1:0.7. This may be because most lighting design guidelines consider only horizontal surfaces for lighting sufficiency and ignore the importance of vertical surfaces.
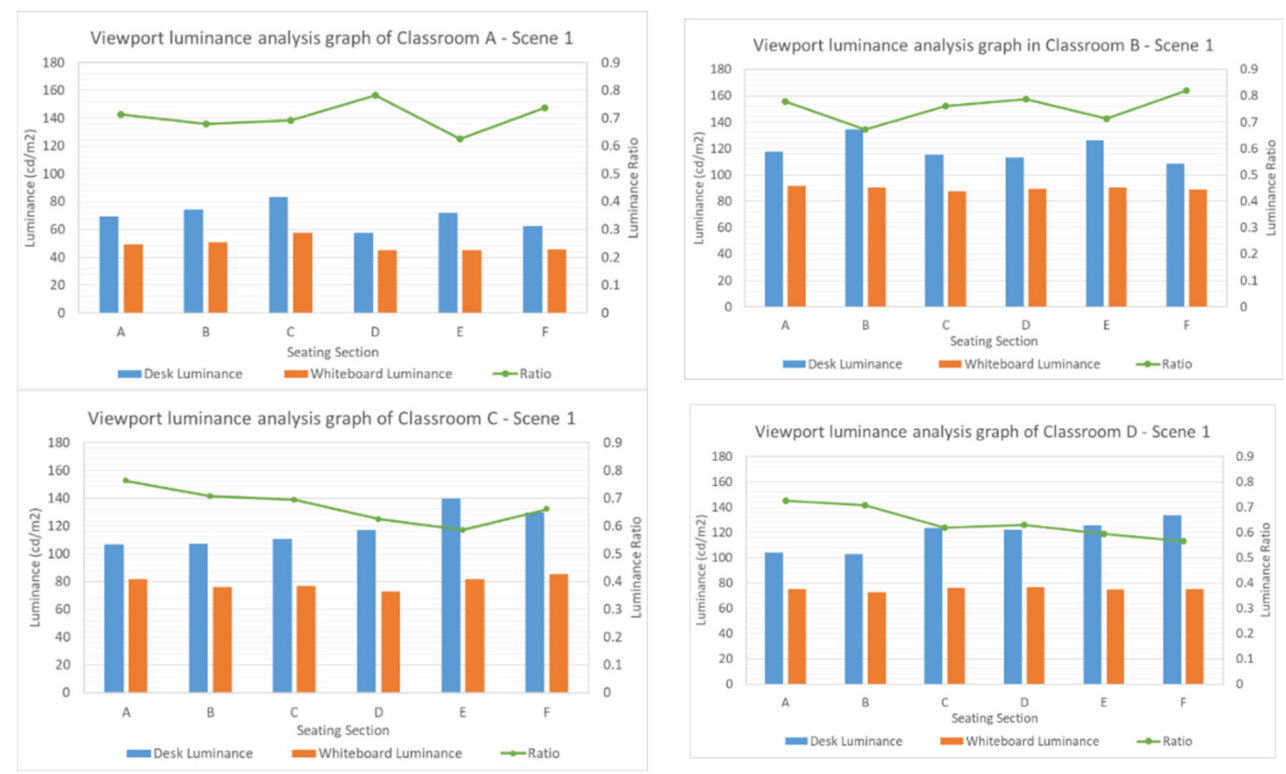

Figure 20. Viewport luminance analysis graph of Classrooms A, B, C, and D-Scene 1 (see Appendix B for large images).

In reality, students must constantly switch between looking at the desk and at the whiteboard. It can even be argued that the whiteboard is more important than the desk in classroom learning since the whiteboard is the "communication platform" of new information and is always located farther from the user than the desk. An increased luminance of the whiteboard will be more noticeable by users and make it easier for the students to read the lecture material.

Viewport Luminance Analysis for Scene 2

Figure 21 shows the viewport luminance analysis of Scene 2. The FR section (A-B-C) had lower desk luminance compared with that of the BR section (D-E-F). The mean luminance ratio between the desk and whiteboard for the front section in Classrooms A and B was approximately 1:1, and in Classrooms C and D, it was approximately $1: 1.4$, in which the whiteboard was almost $50 \%$ brighter than the desk. On the other hand, the mean luminance ratio between the desk and whiteboard for the back section was only 1:0.2. The whiteboard was $80 \%$ darker than the desk. Such a large difference in the luminance ratio suggests that there may be a difference in the user's visual comfort between sitting in the FR and sitting in the BR. This issue will be further discussed in the next chapters. 
The mean luminance ratio between the projection screen and whiteboard was 3.8:1. The projection screen was almost 4 times brighter than the whiteboard surface. Since the projection screen was right next to the whiteboard, the amount of luminance contrast was enough to undermine the perception of information on the whiteboard. Unfortunately, the lecture sessions in all the classrooms that used the projector also used the whiteboard to explain the lecture materials. This can be troublesome for students since the visual tasks switch between the projection screen and the whiteboard.

Furthermore, the difference in luminance in Scene 2 may also influence how students decide on where to sit during the lecture. By sitting in the FR section, it will be easier for them to perceive the lecture content displayed on the vertical surfaces (the whiteboard and the projection screen) (Figure 21) but difficult to perform tasks on the horizontal surface (desk) with a low luminance value. By sitting in the BR section, there is more than adequate light for students to perform tasks on the horizontal surface. However, they have to constantly switch between the well-illuminated desk and the dim vertical surface. The need to constantly adjust their eyes may also cause discomfort.
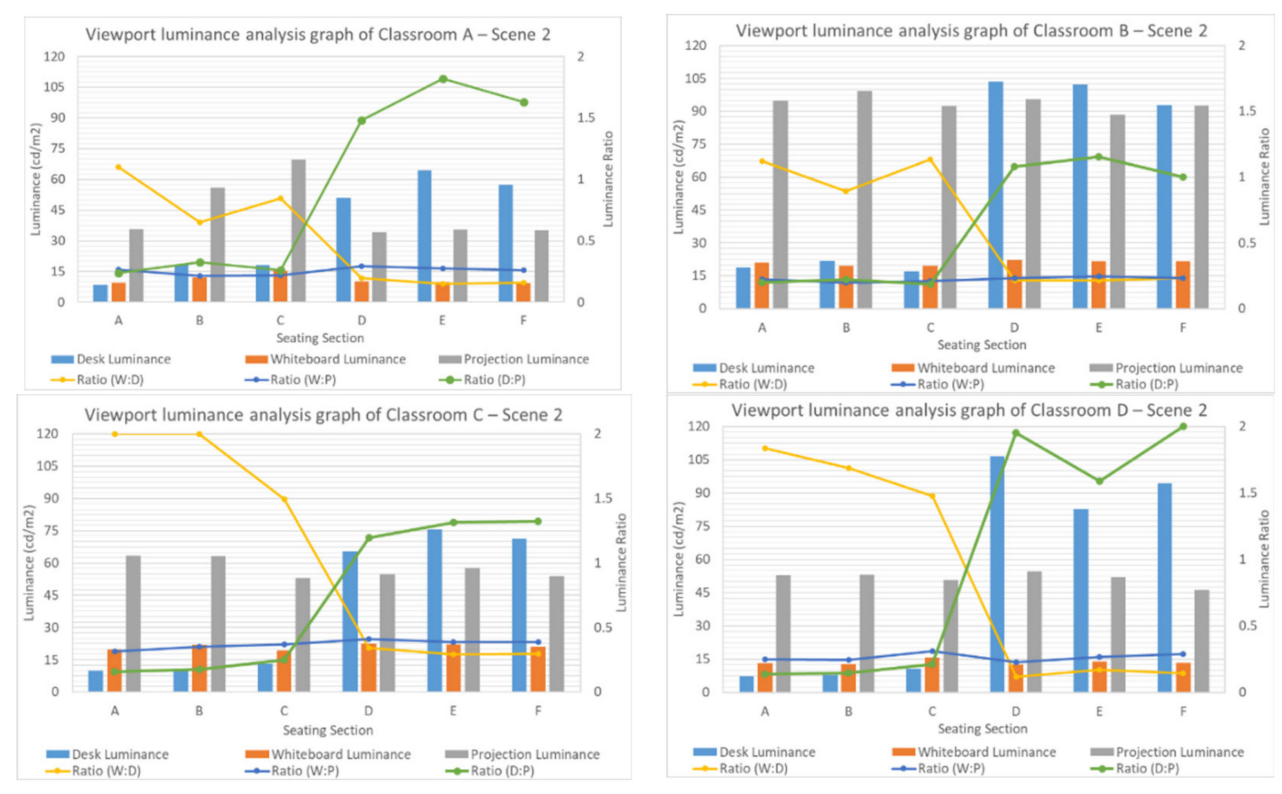

Figure 21. Viewport luminance analysis graph of Classrooms A, B, C, and D-Scene 2 (see Appendix C for large images).

\subsubsection{False Color Image Analysis}

False color images were generated from the calibrated HDRis using hdrscope software. All false color images represent the luminance distribution of the viewport and may portray the human sensation when viewing the viewport, for instance, which part is bright and which part is dark. All of the false color images were positioned according to the classroom arrangement. False color images were rendered using two different scales, one being $100 \mathrm{~cd} / \mathrm{m}^{2}$ and the other being $500 \mathrm{~cd} / \mathrm{m}^{2}$. This is because in Scene 2, the luminance values were low, so the scale needed to be altered to be able to analyze the whole image.

As shown in Figure 22, in Classrooms A and B (Scene 1), the FR light fixture was positioned too close to the whiteboard, creating light scallops on the vertical surface. This may cause distraction because of the existence of repetitive and unusual light patterns on the task surface. In contrast, this phenomenon does not occur in Classrooms C and D (Scene 1) since the FR light fixture is positioned slightly farther from the whiteboard.

In Scene 2, when sitting in the BR, the light from the light fixture falls onto the wall either on the left- or right-hand side of the room. The light causes the walls in the field of view to be well lit and, in some cases, even brighter than the projection screen. This may also cause disturbances in the field of view because of the existence of various bright objects across the field of view. 


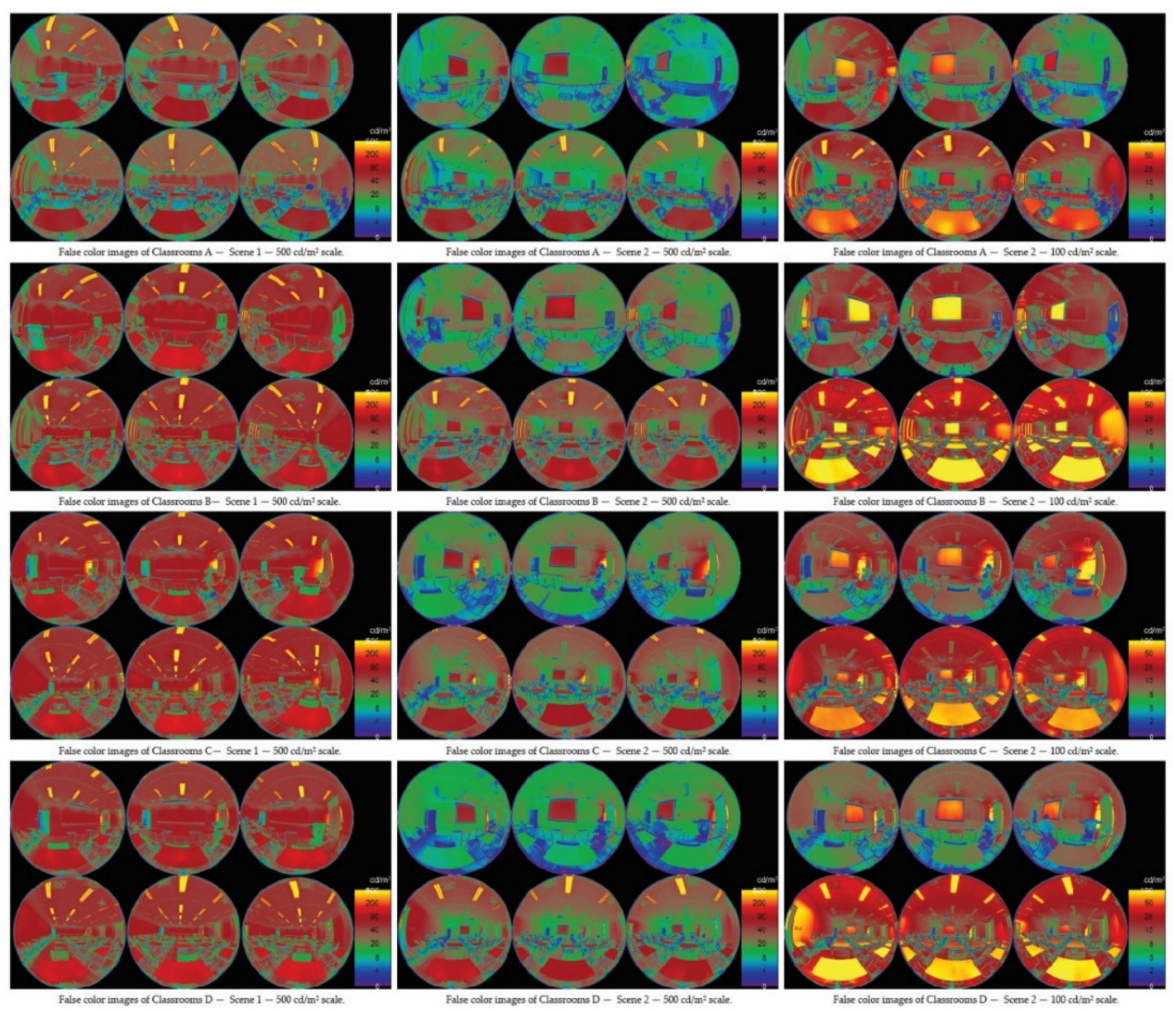

Figure 22. False color images of Classrooms A, B, C, and D for Scene 1 and Scene 2 in two different scales $100 \mathrm{~cd} / \mathrm{m}^{2}$ and $500 \mathrm{~cd} / \mathrm{m}^{2}$ (see Appendix D for large images).

False color images of Scene 2 support the previous analysis of the projection screen having adequate luminance contrast with its surroundings. In all Scene 2 false color images, the projection screen can easily be distinguished from its surroundings. However, the whiteboard next to the projection screen is also a task surface. In the false color images, the color of the whiteboard cannot be separated from its surroundings. The lack of contrast explains why the whiteboard is perceived with a relative "lack of clarity" (Part B, Question 10 in the questionnaire) from the user's point of view.

Last, from the false color images, it can be argued that the strategy of using draperies to block sunlight works quite well in these classrooms. In all cases, the sun does not fall on or reflect off the whiteboard, even though the whiteboard surface is glossy. However, with this strategy, the amount of daylight entering the room is quite low, and artificial lighting is always needed. Even so, when the window is in the field of view, a speck of sunlight can still be seen, which may cause discomfort to the eye due to the high luminance contrast between the indoor and outdoor environment.

\subsubsection{Glare Analysis}

Glare analysis was performed using Evalglare desktop software. The cutting field of view was enabled to mimic the human field of view using both eyes. UGR and DGP were the two metrics being recorded for analysis. UGR is the CIE glare index for indoor lighting, whereas DGP shows a strong correlation with the user's response in the daylit space [21,22]. Glare analysis was employed on all viewports with both lighting arrangement scenes. All glare analysis rendered images are positioned according to the classroom arrangement.

For UGR metrics, glare is considered imperceptible when the scale is smaller than 13 , perceptible when the scale is between 13 and 22, and disturbing and intolerable when the scale is large than 22 . As shown in Table 6, in Scene 1, Classrooms B, C, and D all exhibited perceptible glare in both FR and BR seats. This indicates that the light intensity from the lighting fixtures may be slightly too strong. In Scene 2, only the viewports in the FR of Classroom C showed perceptible glare. Upon further investigation, it was found from the images of Classroom C in Figure 23 that the glare source 
was daylight on the wall next to the whiteboard. Its luminance value was approximately $250 \mathrm{~cd} / \mathrm{m}^{2}$. On the other hand, the DGP values from all viewports were well under 0.35 , indicating imperceptible daylight glare. This suggests that the observed "on spot" daylight glare source behaviors are more similar to a lighting fixture. It was noted that UGR values are well correlated with the results from Part B Questionnaire (Section 3.1.2). A strong sentiment of the whiteboard glare (Q.9) was found in Classroom D (Lighting Scene 1). A mild sentiment of the project screen (Q.6) glare was found in Classroom C (Lighting Scene 2).

Table 6. Unified Glare Rating (UGR) value of subjects in Scene 1 and Scene 2.

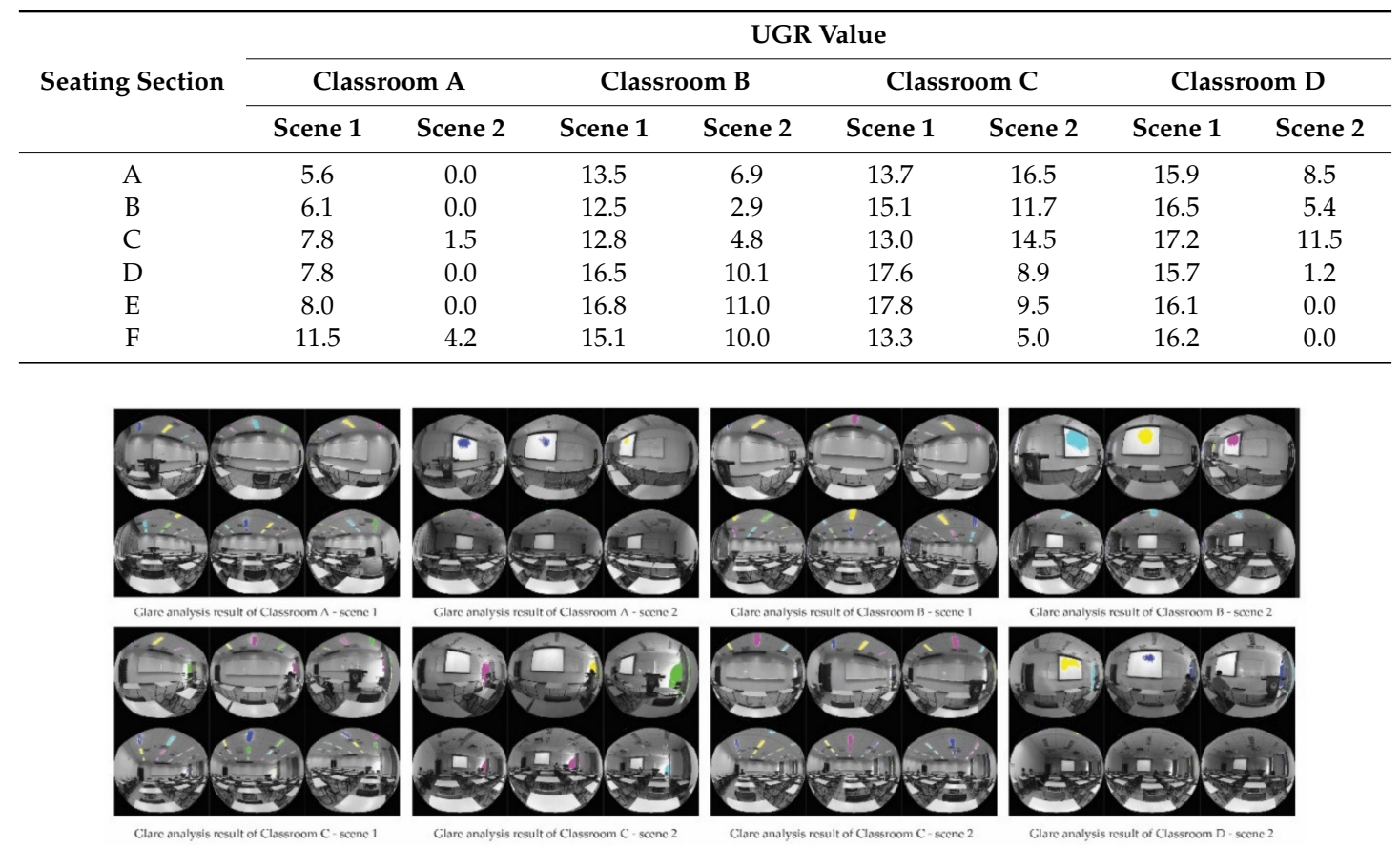

Figure 23. Glare analysis of Classroom A, B, C, and D for Scene 1 and Scene 2 (see Appendix E for large images).

From the glare analysis images (Figure 23), it can be seen that in most cases Evalglare recognized artificial lighting as glare sources in both Scene 1 and Scene 2. Regarding the FR of Scene 2, Evalglare recognized parts of the projection screen as a glare source. In scenes where either the sky or sun can be seen directly, Evalglare also recognized it as a glare source. These images provide an intuitive and effective way to communicate the location of glare problems that need to be first addressed.

\section{Comparisons of Teaching Context and Lighting Senses}

\subsection{Comparison of Visual Comfort between Text-and Image-Based Contents}

Due to the difference in lecture content, there may be a difference in visual comfort between textand image-based content. A comparison of the overall comfort level is shown in Figure 24. Overall comfort for image-based subjects was split in half, while for text-based subjects, $66 \%$ of the respondents picked comfortable, and the remaining $34 \%$ picked uncomfortable.

However, the overall comfort level alone draws only a partial picture. When the mean value of task performance and visual annoyance is considered, it can be seen from the graph (Figure 15) that image-based subjects (Classrooms A and B) had higher mean values than text-based subjects (Classrooms C and D), especially in the third and fourth question groups (seeing the whiteboard and seeing the projector). This is because text-based content demands higher visual acuity than image-based content since every detail (letters, numbers, and symbols) needs to be clearly recognized to be able to entirely grasp the lecture material. This indicates that even with a low level of visual 
comfort during lecture sessions, text-based content that is embedded with precise messages are still favored over image-based content for overall comfort.

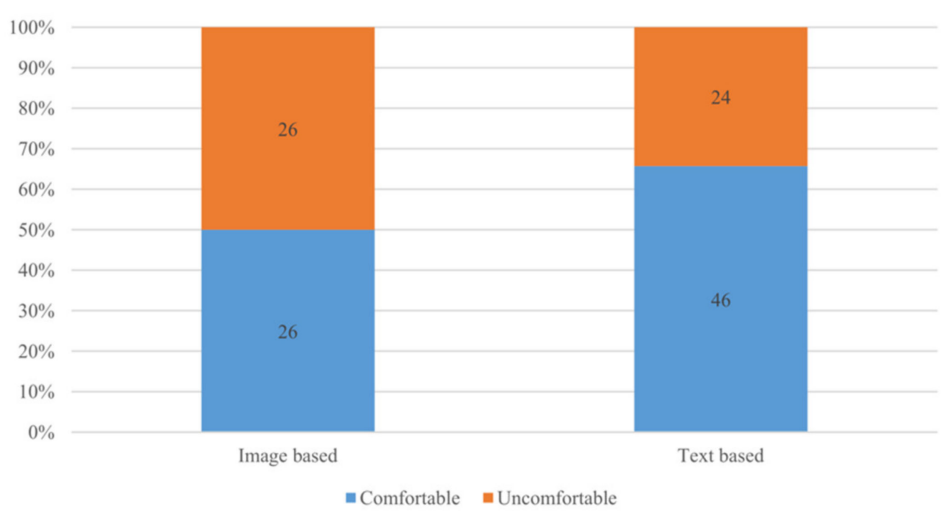

Figure 24. Comparison of overall comfort level between image-based subject and text-based subject.

\subsection{Comparison of Overall Comfort Level between Scene 1 and Scene 2}

Regarding the difference between the lighting scenes, users of Scene 1 (Classroom D) had a more satisfactory experience. Seventy-three percent of the respondents in Scene 1 answered "comfortable", while only $52 \%$ of the respondents in Scene 2 (Classrooms A, B, C) answered "comfortable"(Figure 25). Spaces with high luminance uniformity are more appreciated than those with high visual contrast.

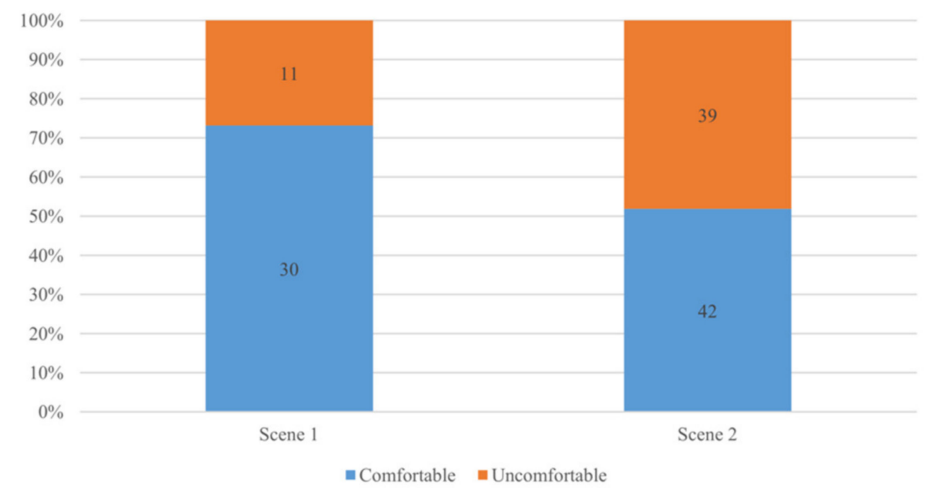

Figure 25. Comparison of overall comfort level between Scene 1 and Scene 2.

\section{Summary and Conclusions}

Daylight glare, luminance distribution, discomfort glare, daylight availability, lighting scenes and illuminance uniformity have been ranked atop in the contributing factors to visual comfort [14]. The classrooms in the study chose to sacrifice daylight availability to prevent glare problems and improve luminance distribution. However, the existing lighting scenes still cannot provide a satisfactory luminance distribution and illuminance uniformity. The visual comfort problems were well documented in the responses of the questionnaire survey.

In the past decade, educational media in university classrooms has continued to evolve. Increasing numbers of self-lit devices (projectors, laptops, LED TVs, etc.) are now classroom tools. Today, there are at least three working surfaces in a classroom that students must focus on: the desk (horizontal-task surface), the whiteboard, and the projection screen (both vertical-task surfaces). By applying HDRi spatial luminance mapping technique, this study was able to simultaneously measure the luminance of the three working surfaces as well as that of their surroundings. It allows the investigation of the key contributing factors in visual comfort in the space with multiple working surfaces and complex light sources. The key findings of this study are summarized as follows: 
1. The DI of the subject classroom is more than adequate when all lights are on (Scene 1 ). The average illuminance of 776 lux is larger than the required 500 lux $[25,26]$. Coincidentally, 39\% of students in Classroom D who experienced Scene 1 find that the overall lighting level in the room was too bright.

2. In Scene 2, where the projector is on with the FR lights off and the BR lights on (Classrooms A, B, and C), the DI of the FR section becomes too low, with an average value of 105 lux. In contrast, the DI of the BR section is still above 500 Lux.

3. Due to the constant use of curtains to block the daylight in classrooms, daylight has little to no effect on the luminance in the classroom. Daylight even becomes a glare source in Classroom C with Scene 2 lighting arrangements.

4. The desk surface is the brightest and has the highest visual comfort among the three surfaces. The average luminance ratio between the desk and whiteboard is approximately 1 to 0.7 in Scene 1 and 1 to 0.2 in Scene 2. Additionally, from the false color image analysis, unintended light scallops and unintended bright light also fall on vertical surfaces, creating distractions.

5. The luminance ratio between the projection screen and whiteboard is 3 to 1 . Nevertheless, the mean value of the projector task performance number is low compared with that of the desk-based task.

6. The projection screen cannot be used simultaneously with the whiteboard. The increase in luminance in one surface results in the loss of clarity in the other surface. In the false color image analysis of Scene 2, the projection screen is easy to distinguish from the surroundings, whereas the whiteboard is almost invisible because it has no clear boundary with the adjacent wall surfaces.

7. UGR is better than DGP in identifying glare in this study. It was able to identify both the glare from the excessive lighting in Scene 1 and the daylight glare in Classroom C in Scene 2. In contrast, DGP from all viewports shows only imperceptible glare.

8. Physical symptoms are not always associated with discomfort. Some respondents experienced physical symptoms while answering "comfortable" for their overall comfort level.

9. Among all the respondents answering "uncomfortable", the most perceived cause of discomfort is artificial lighting quality ( $49 \%)$, followed by inadequate projector brightness ( $35 \%)$.

10. Scene 2 has the tendency to be perceived as "slightly too dark", while Scene 1 has the tendency to be perceived as "slightly too bright".

11. The text-based class is perceived as more comfortable than the image-based class ( $66 \%$ to $50 \%$ ). However, in comparison to their task performance mean value, the image-based class has a higher score than those of the text-based class.

Recommendations for improving university classroom lighting design were drawn from the above findings and are listed below:

1. For the current classroom use pattern, a new row of linear floodlights, parallel to the whiteboard, should be added with individual lighting fixture control; they should be close to the whiteboard/front wall vertical surface. In operation, only the new row of lights changes settings according to different teaching scenarios. The lights in the FR section and the lights in the BR will always be on. It will ease the luminance imbalance between the projector screen and whiteboard as well as between the FR and BR seating sections.

2. The lumen outputs of each lighting fixture can be reduced by $30 \%$. It saves energy and reduces glare. The DI would still be approximately 500 lux.

3. It may be worth considering changing the design criteria of classroom lighting from illuminance-based spot measurement criteria $[25,26]$ to HDRi-based spatial luminance mapping. The technology is established and provides a comprehensive measure of the combined effects in classroom lighting.

4. A different daylight control mechanism should be considered for effective daylight utilization. 
Author Contributions: Conceptualization, Y.-S.C. and S.S.; methodology, Y.-S.C. and S.S.; formal analysis, Y.-S.C., S.S. and D.P.S.; investigation, S.S.; resources, Y.-S.C.; data curation, Y.-S.C., S.S. and D.P.S.; writing, Y.-S.C., S.S. and D.P.S; visualization, Y.-S.C., S.S. and D.P.S.; project administration, Y.-S.C. and S.S.; funding acquisition, Y.-S.C. All authors have read and agreed to the published version of the manuscript.

Funding: This research was funded by the Taiwan Ministry of Science and Technology, grant number MOST 106-2221-E-011-051.

Acknowledgments: The authors are grateful to the students in NTUST who participated in the questionnaire survey.

Conflicts of Interest: The authors declare no conflicts of interest.

\section{Appendix A. HDR Images Compiled in Figure 19}

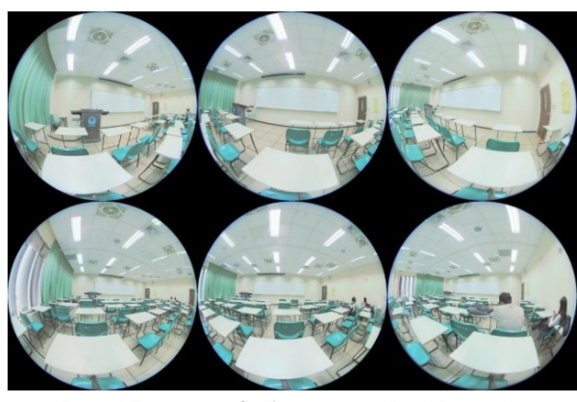

HDR Images of Classroom A-Scene 1.

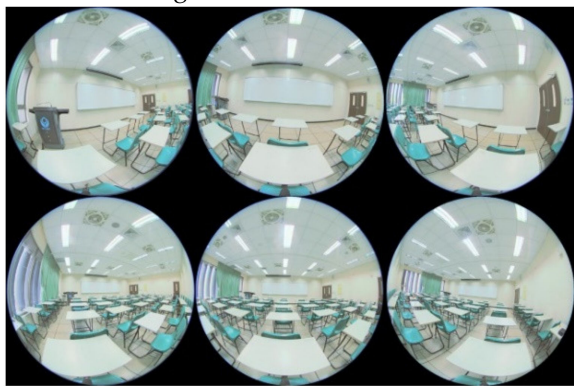

HDR Images of Classroom B-Scene 1.

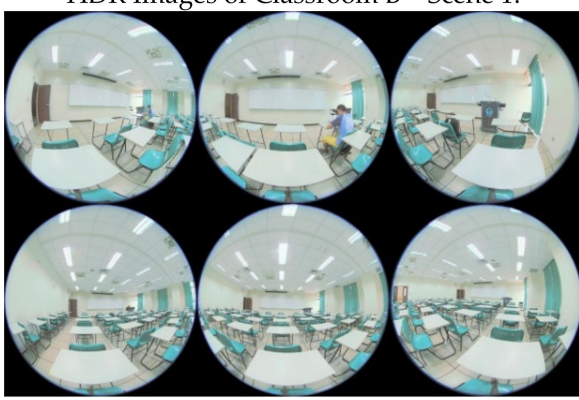

HDR Images of Classroom C-Scene 1.

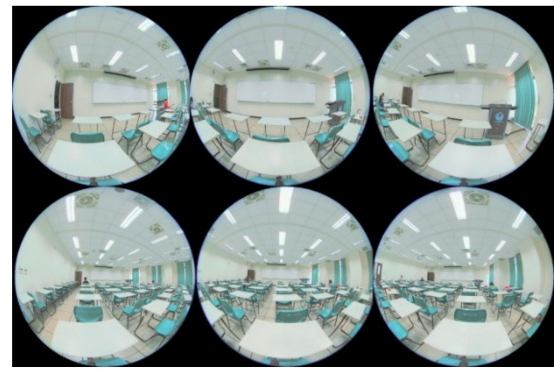

HDR Images of Classroom D-Scene 1.

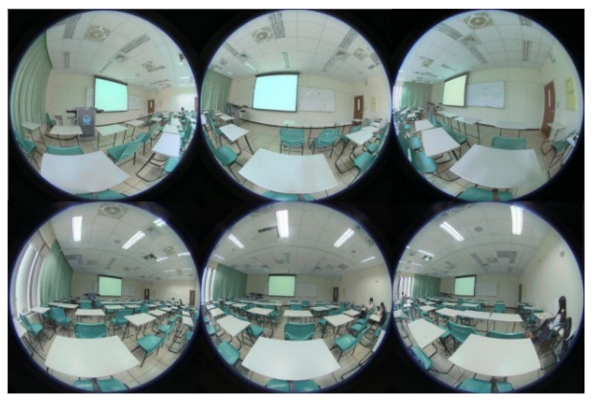

HDR Images of Classroom A-Scene 2.

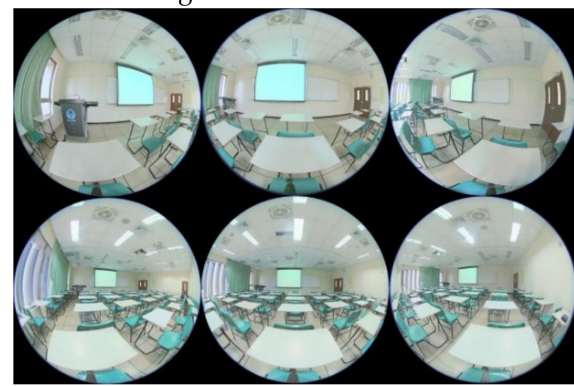

HDR Images of Classroom B-Scene 2.

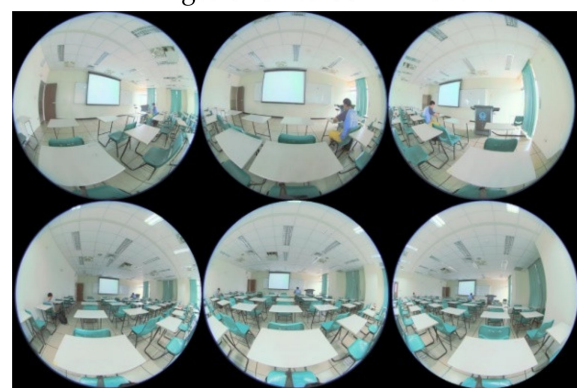

HDR Images of Classroom C-Scene 2.

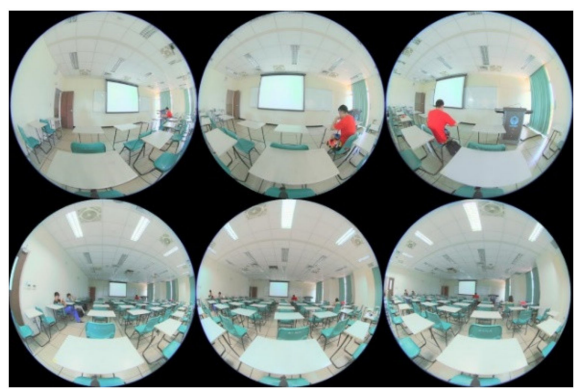

HDR Images of Classroom D-Scene 2. 
Appendix B. Viewport Luminance Analysis Graphs Compiled in Figure 20
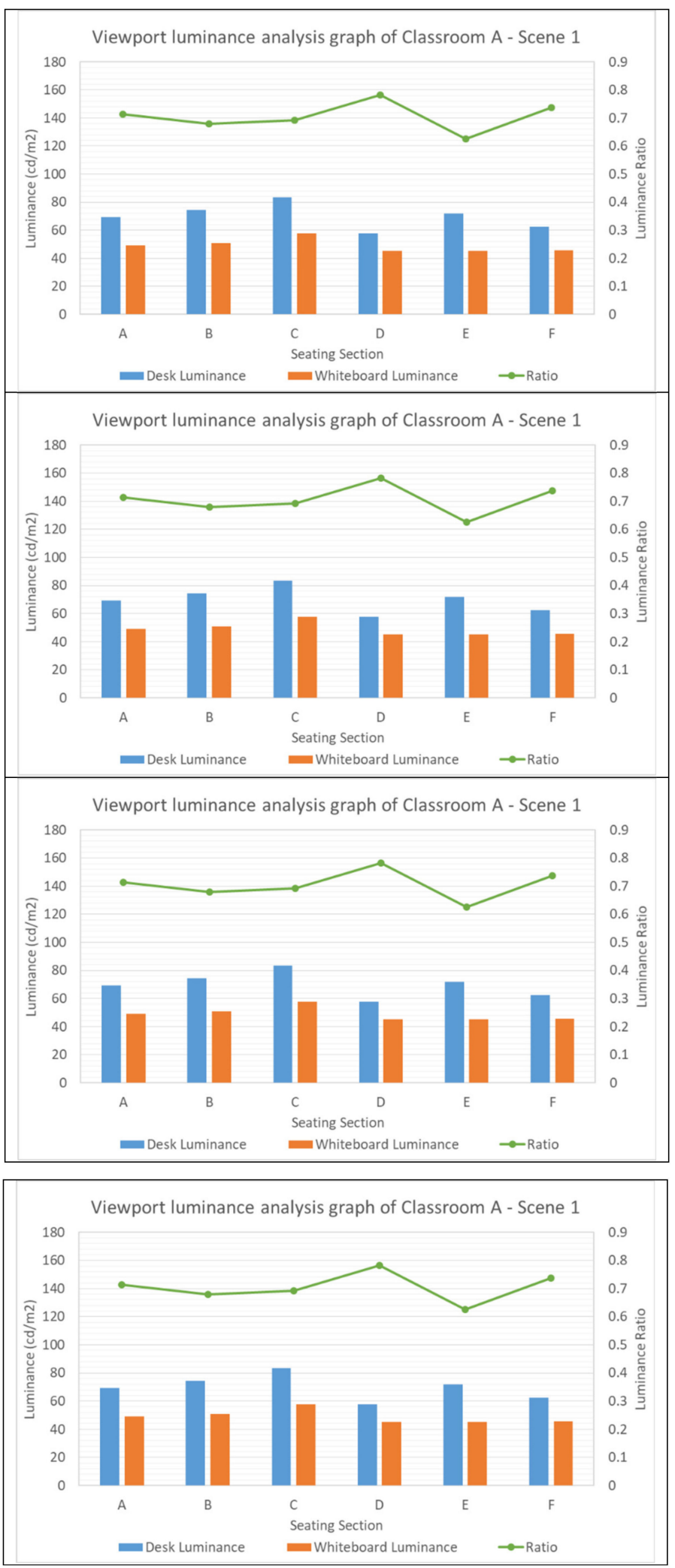
Appendix C. Viewport Luminance Analysis Graphs Compiled in Figure 21
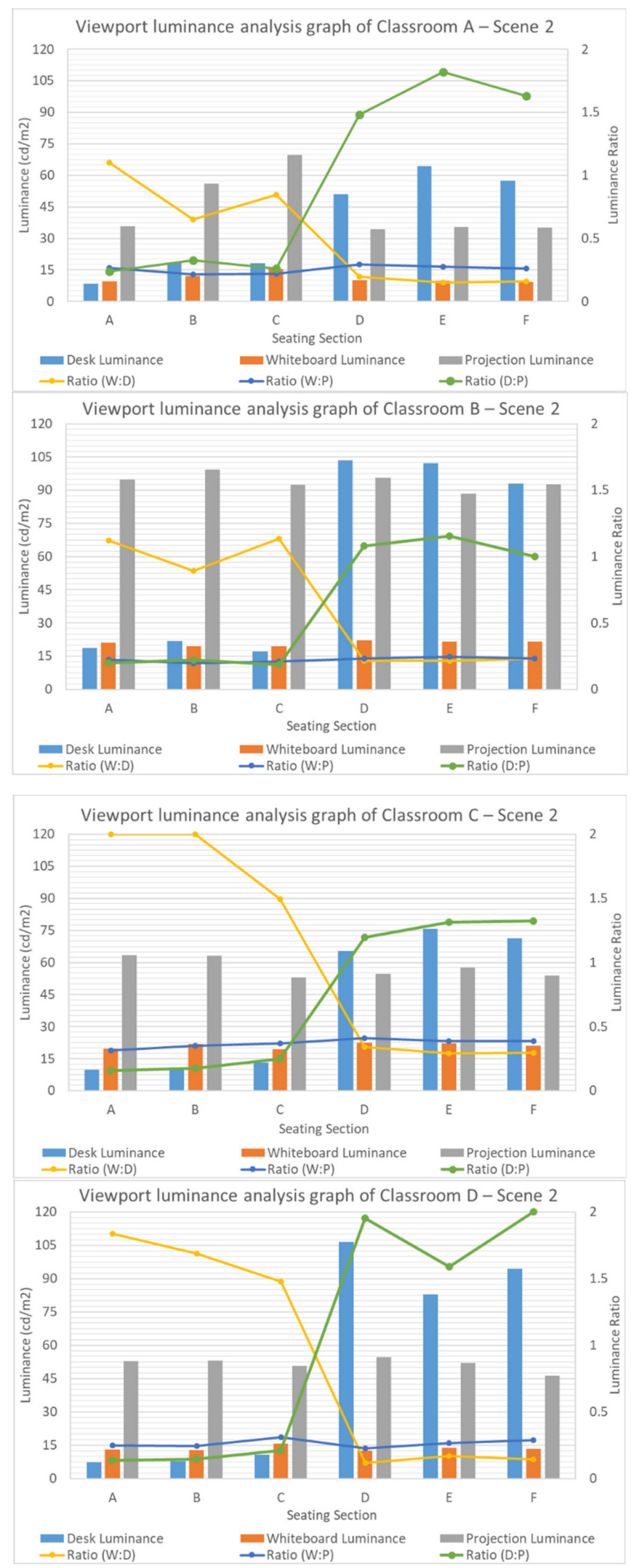
Appendix D. Luminance False Color Graphs Compiled in Figure 22

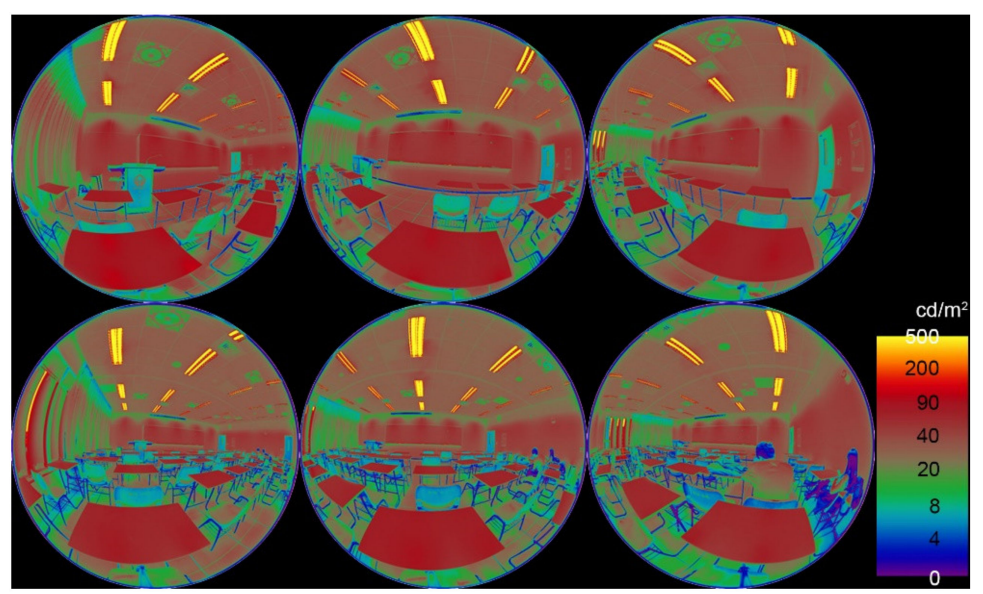

Luminance false color graph of Classroom A-Scene 1 (Threshold: $500 \mathrm{~cd} / \mathrm{m}^{2}$ ).

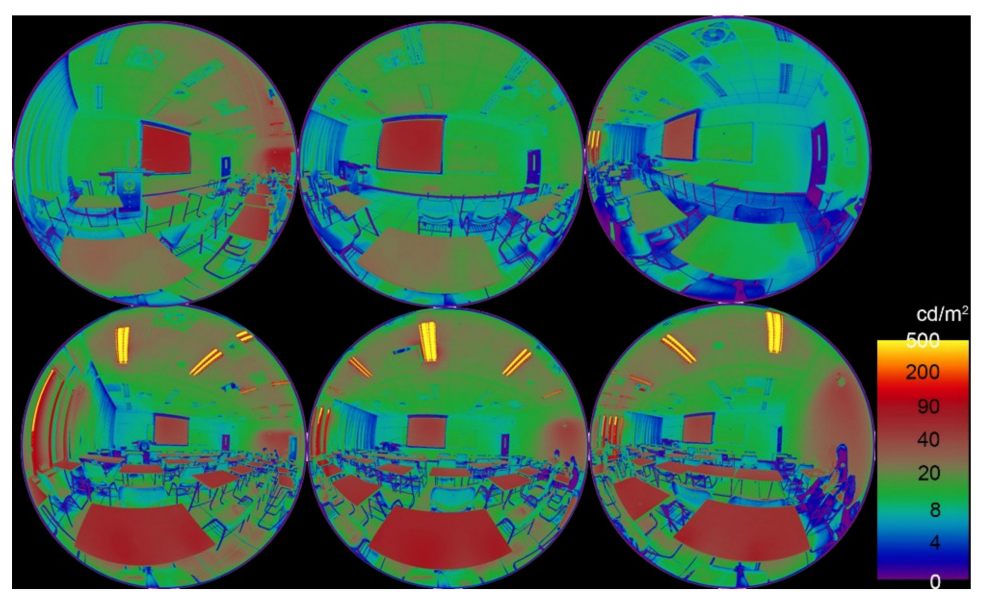

Luminance false color graph of Classroom A-Scene 2 (Threshold: $500 \mathrm{~cd} / \mathrm{m}^{2}$ ).

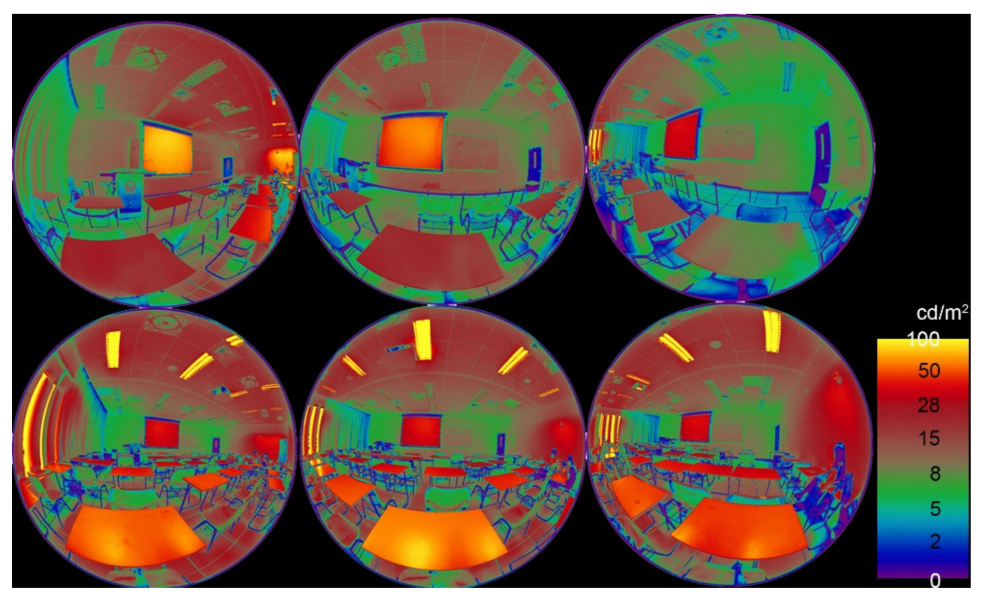

Luminance false color graph of Classroom A-Scene 2 (Threshold: $100 \mathrm{~cd} / \mathrm{m}^{2}$ ). 


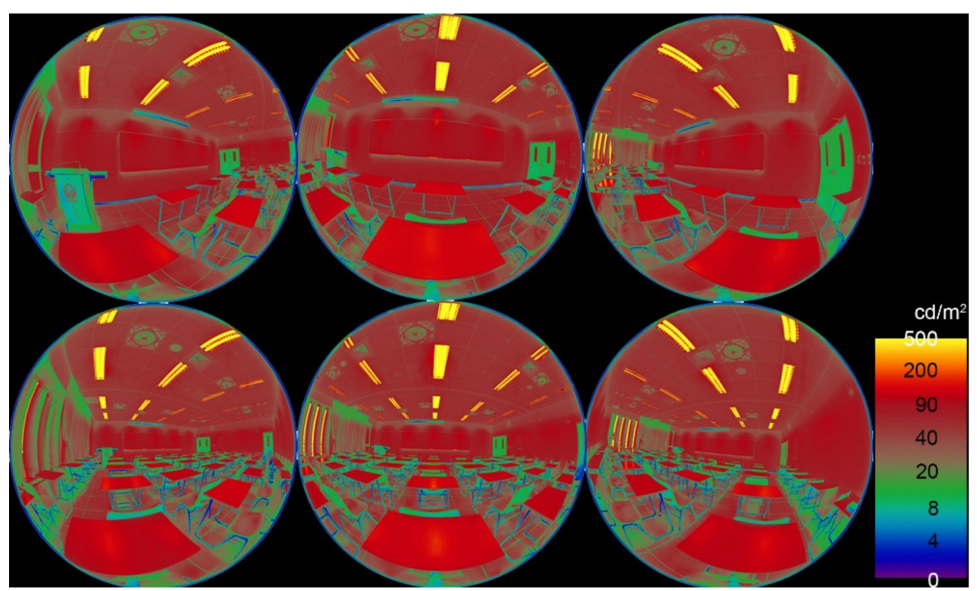

Luminance false color graph of Classroom B-Scene 1 (Threshold: $500 \mathrm{~cd} / \mathrm{m}^{2}$ ).

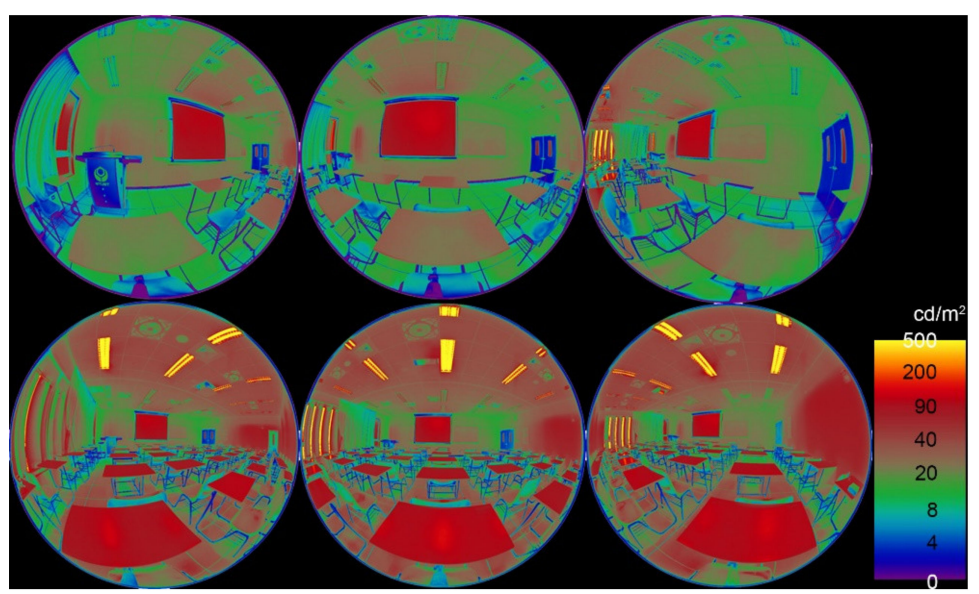

Luminance false color graph of Classroom B-Scene 2 (Threshold: $500 \mathrm{~cd} / \mathrm{m}^{2}$ ).

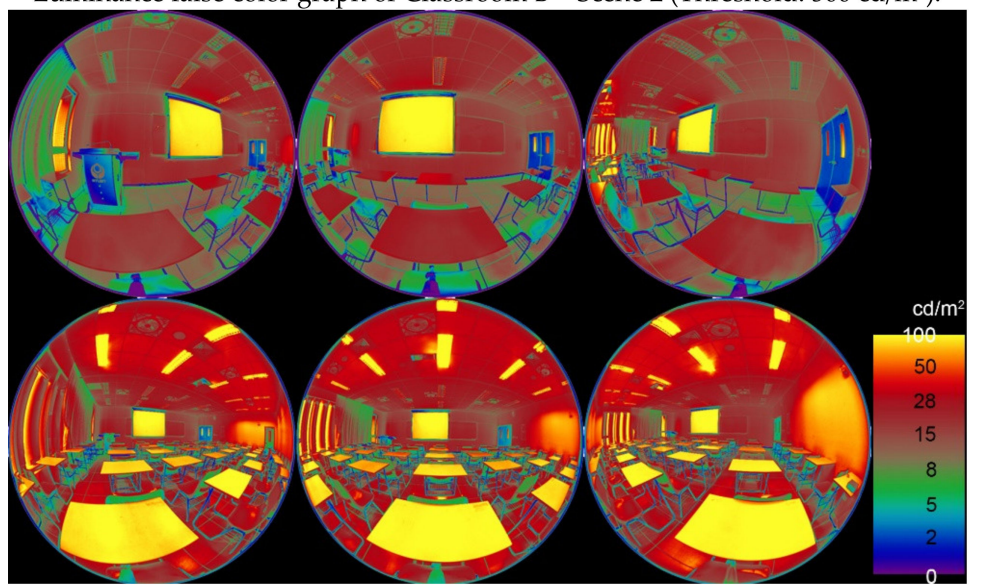

Luminance false color graph of Classroom B-Scene 2 (Threshold: $100 \mathrm{~cd} / \mathrm{m}^{2}$ ). 


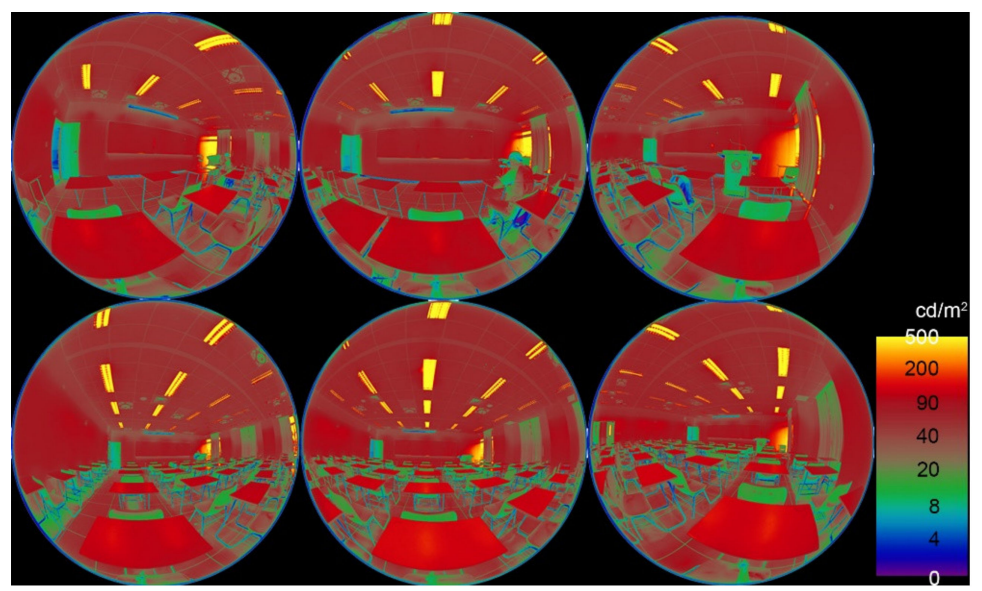

Luminance false color graph of Classroom C-Scene 1 (Threshold: $\left.500 \mathrm{~cd} / \mathrm{m}^{2}\right)$.

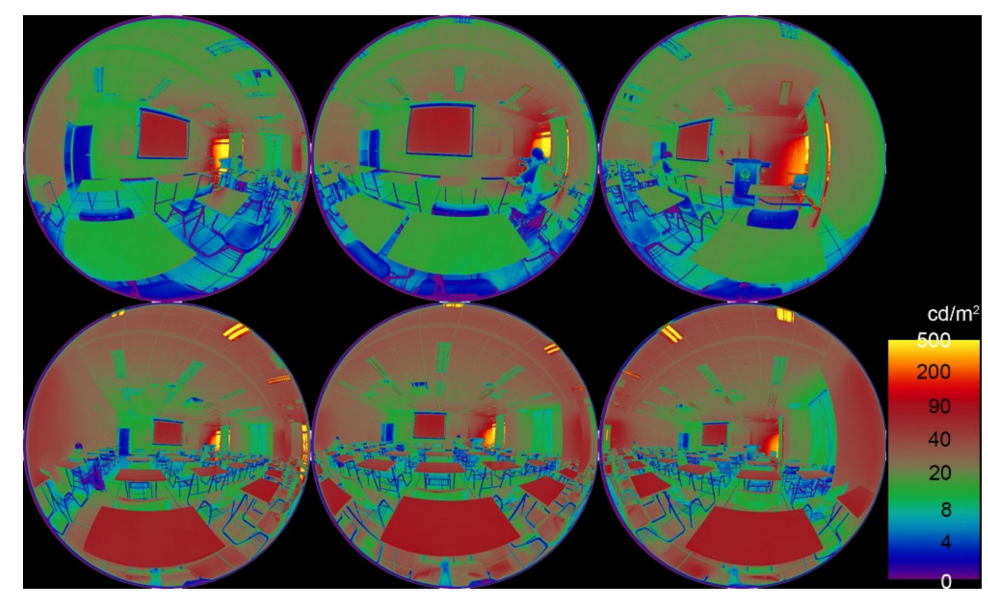

Luminance false color graph of Classroom C-Scene 2 (Threshold: $500 \mathrm{~cd} / \mathrm{m}^{2}$ ).

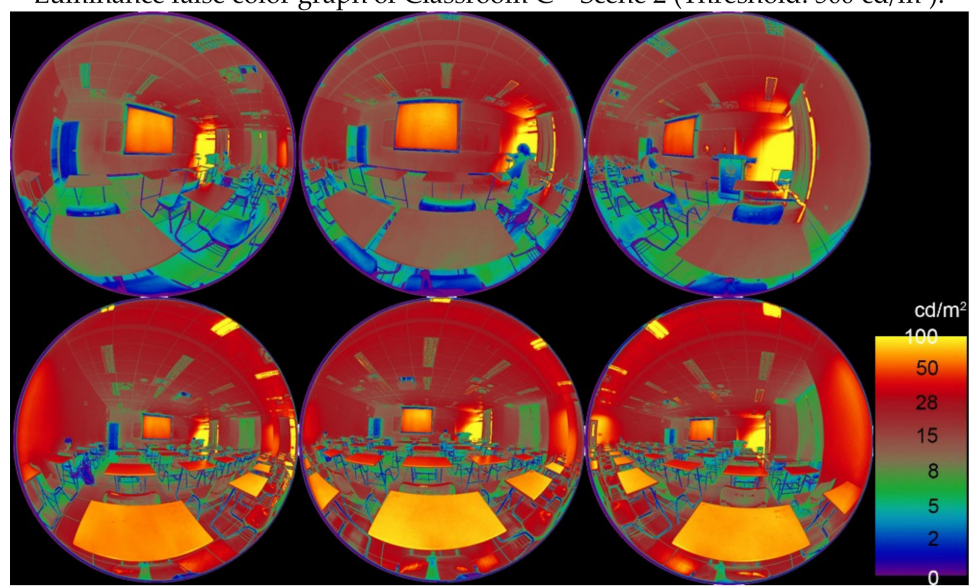

Luminance false color graph of Classroom C-Scene 2 (Threshold: $100 \mathrm{~cd} / \mathrm{m}^{2}$ ). 


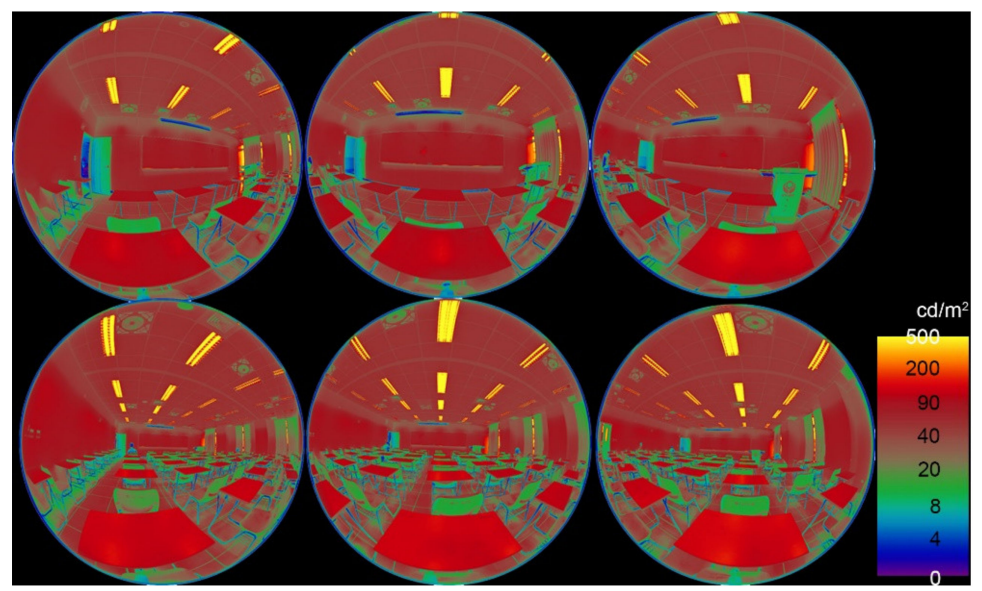

Luminance false color graph of Classroom D-Scene 1 (Threshold: $500 \mathrm{~cd} / \mathrm{m}^{2}$ ).

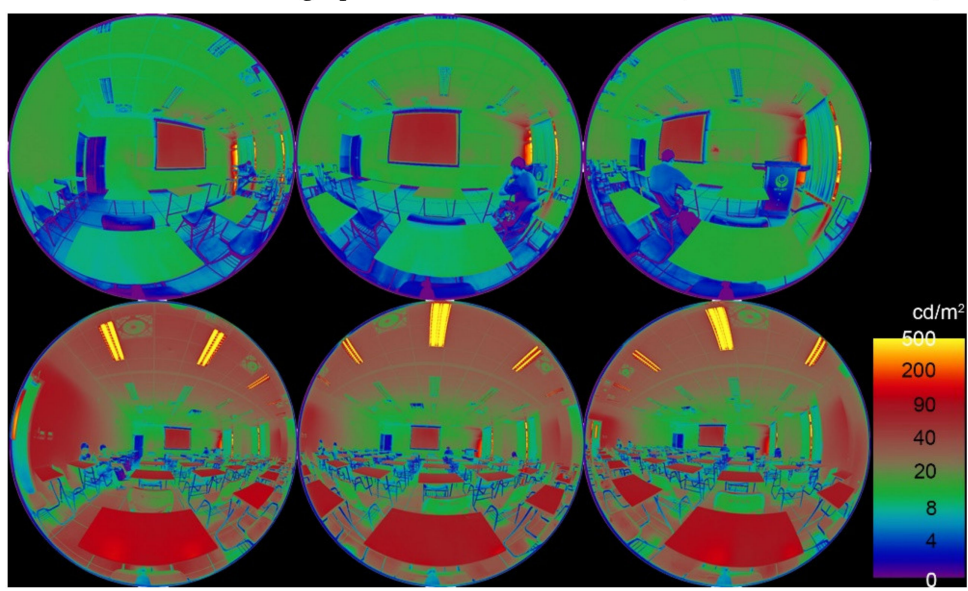

Luminance false color graph of Classroom D-Scene 2 (Threshold: $500 \mathrm{~cd} / \mathrm{m}^{2}$ ).

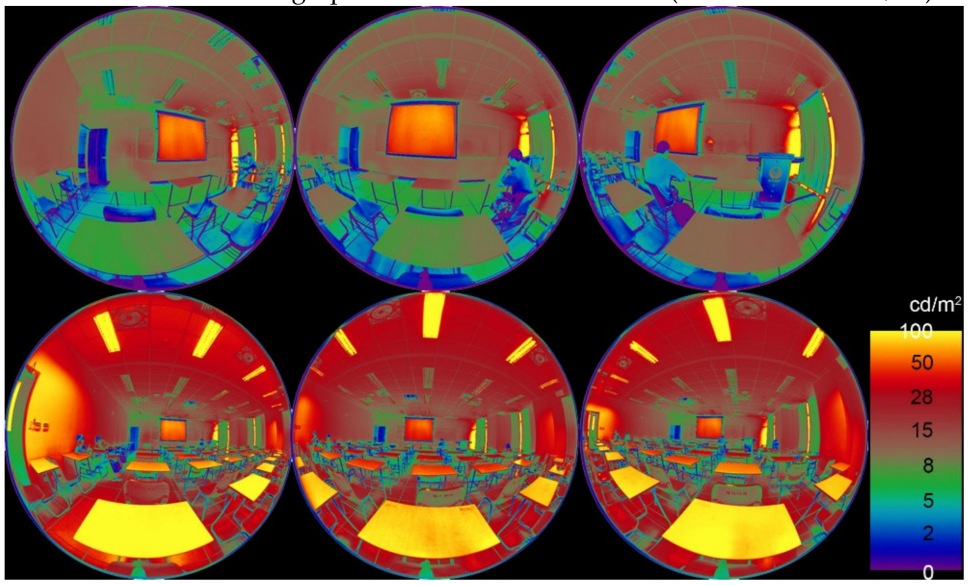

Luminance false color graph of Classroom D-Scene 2 (Threshold: $100 \mathrm{~cd} / \mathrm{m}^{2}$ ). 
Appendix E. Glare Analysis Images Complied in Figure 23

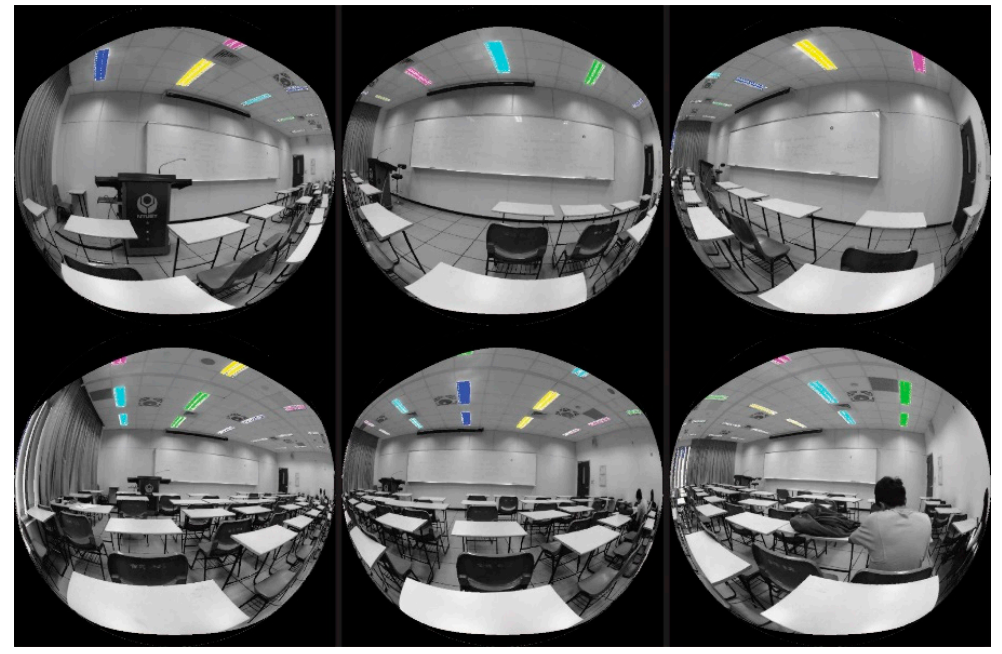

Glare Analysis of Classroom A-Scene 1.

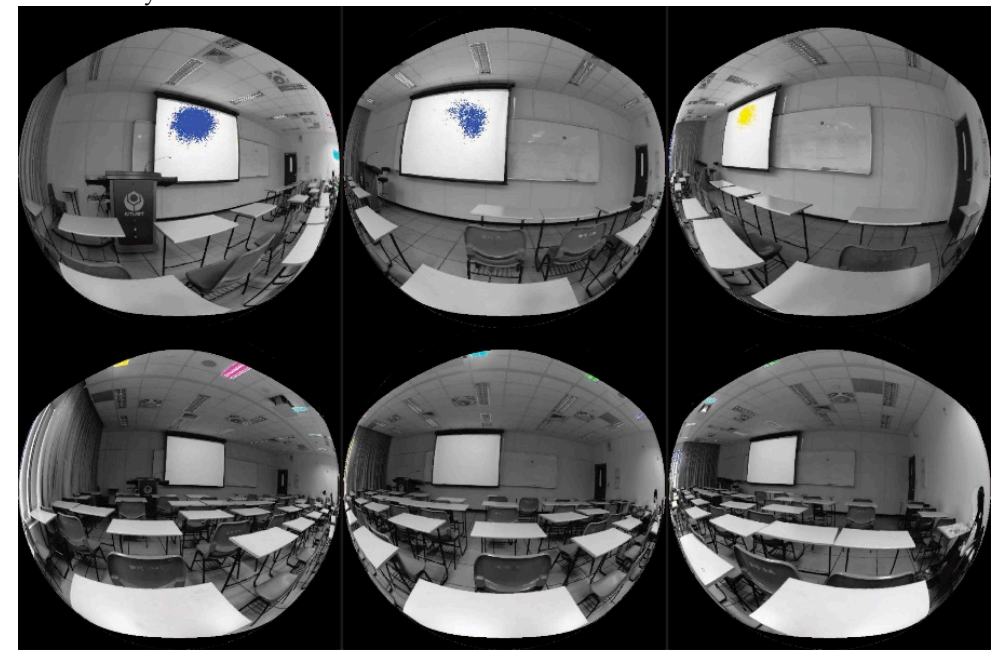

Glare Analysis of Classroom A-Scene 2.

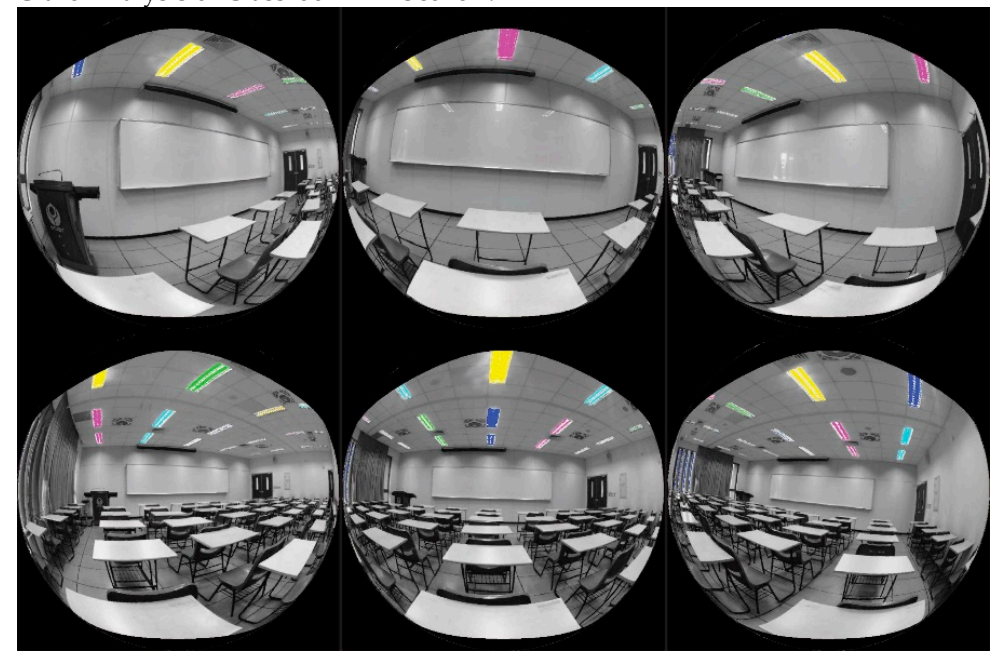

Glare Analysis of Classroom B-Scene 1. 


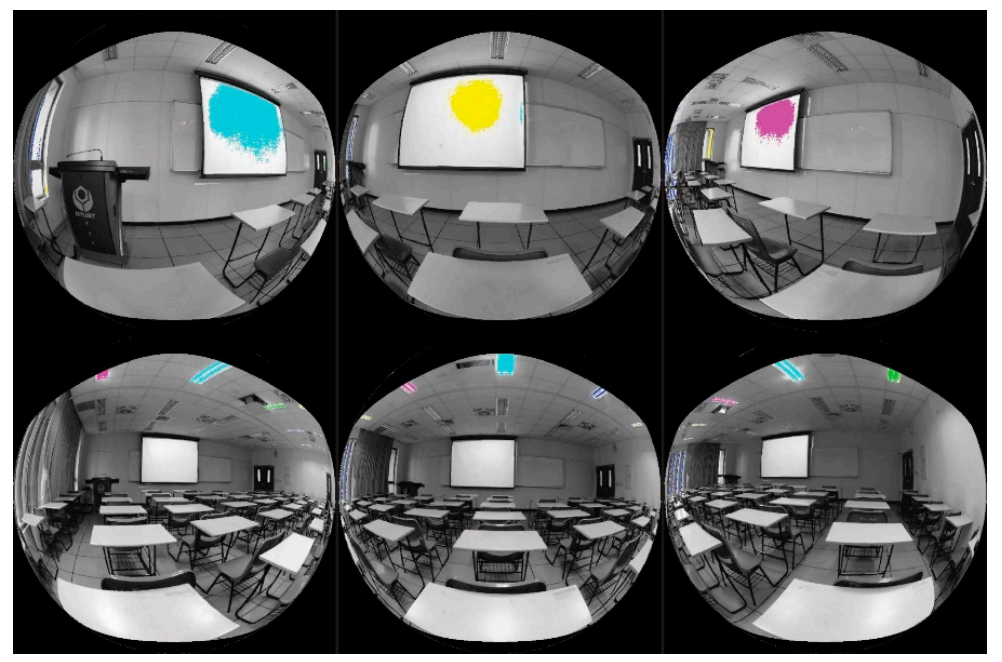

Glare Analysis of Classroom B-Scene 2.

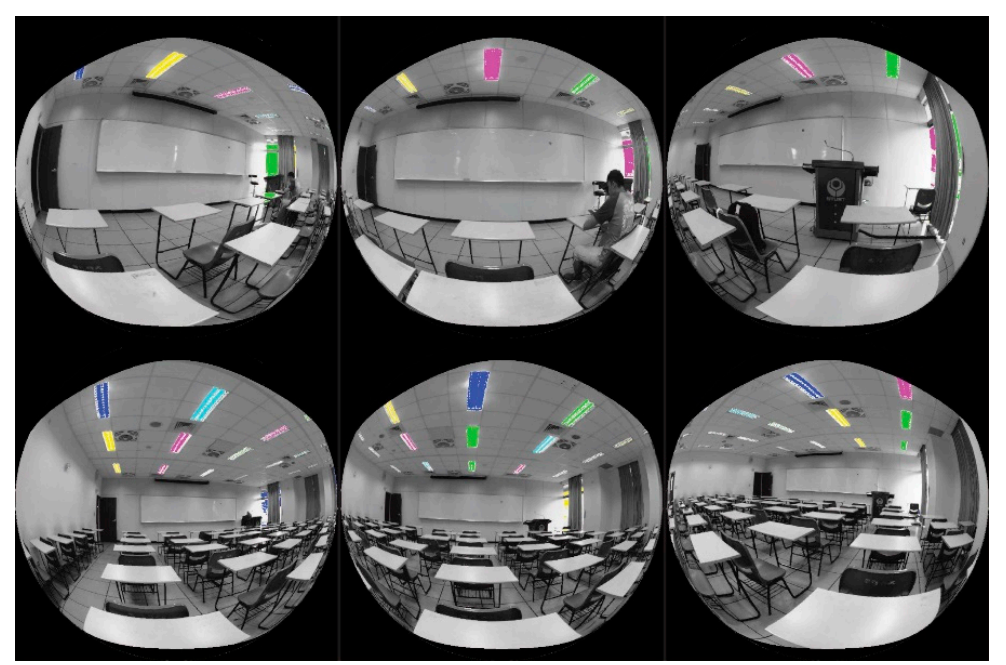

Glare Analysis of Classroom C-Scene 1.

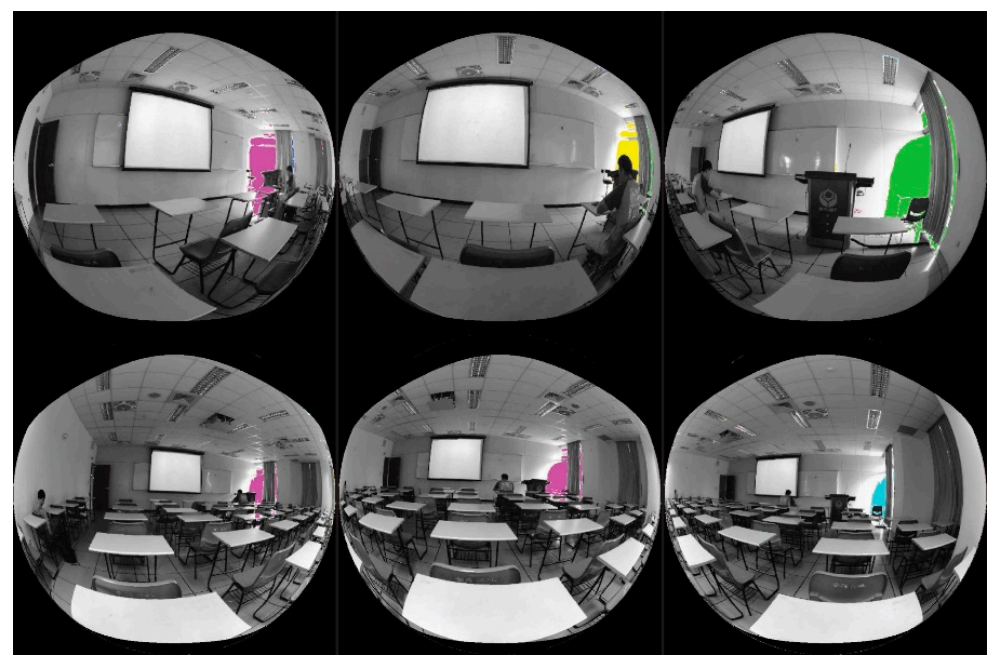

Glare Analysis of Classroom C-Scene 2 

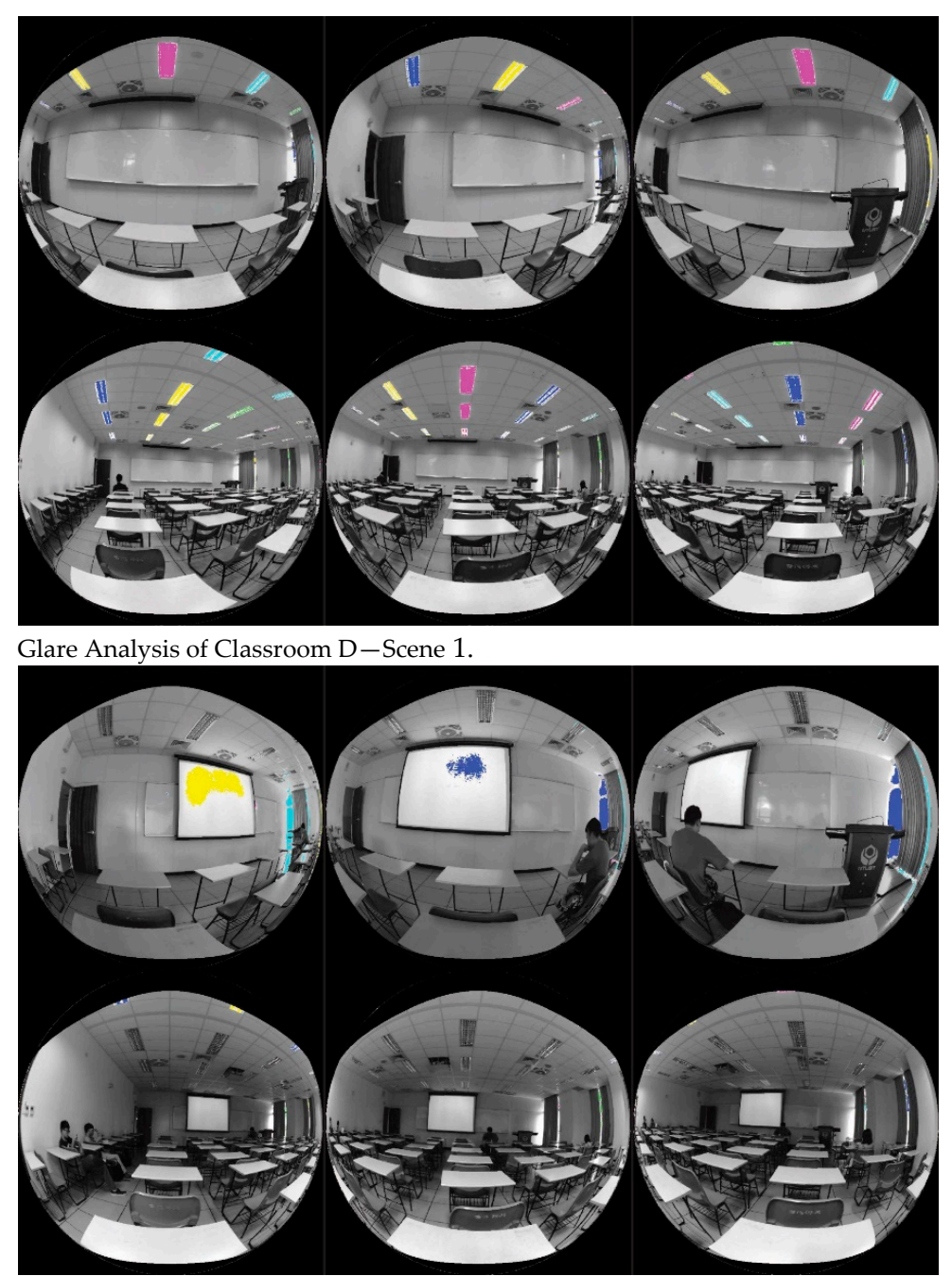

Glare Analysis of Classroom D-Scene 2.

\section{References}

1. Hinckson, E.; Salmon, J.; Benden, M.; Clemes, S.A.; Sudholz, B.; Barber, S.E.; Aminian, S.; Ridgers, N.D. Standing Classrooms: Research and Lessons Learned from Around the World. Sport Med. 2016, 46, $977-987$. [CrossRef] [PubMed]

2. Ibañez, C.A.; Zafraa, J.C.G.; Sachta, H.M. Natural and Artificial Lighting Analysis in a Classroom of Technical Drawing: Measurements and HDR Images Use. Procedia Eng. 2017, 196, 964-971. [CrossRef]

3. Winterbottom, M.; Wilkins, A. Lighting and discomfort in the classroom. J. Environ. Psychol. 2009, $29,63-75$. [CrossRef]

4. Musa, A.R.; Abdullah, N.A.G.; Che-Ani, A.I.; Tawil, N.M.; Tahir, M.M. Indoor Environmental Quality for UKM Architecture Studio: An Analysis on Lighting Performance. Procedia Soc. Behav. Sci. 2012, 60, 318-324. [CrossRef]

5. Castilla, N.; Llinares, C.; Bisegna, F.; Blanca-Giménez, V. Emotional evaluation of lighting in university classrooms: A preliminary study. Front. Archit. Res. 2018, 7, 600-609. [CrossRef]

6. Burattini, C.; Piccardi, L.; Curcio, G.; Ferlazzo, F.; Giannini, A.M.; Bisegna, F. Cold LED lighting affects visual but not acoustic vigilance. Build. Environ. 2019, 151, 148-155. [CrossRef]

7. Nguyen, T.P.L.; Peña-García, A. Users' awareness, attitudes, and perceptions of health risks associated with excessive lighting in night markets: Policy implications for sustainable development. Sustainability 2019, 11, 6091. [CrossRef] 
8. Balocco, C.; Volante, G. A method for sustainable lighting, preventive conservation, energy design and technology-lighting a historical church converted into a university library. Sustainability 2019, 11, 3145. [CrossRef]

9. Jin, H.; Li, X.; Kang, J.; Kong, Z. An evaluation of the lighting environment in the publicspace of shopping centres. Build. Environ. 2017, 115, 228-235. [CrossRef]

10. Cuttle, C. Brightness, lightness, and providing 'a preconceived appearance to the interior'. Light. Res. Technol. 2004, 36, 201-216. [CrossRef]

11. Van Den Wymelenberg, K.; Inanici, M. A Critical Investigation of Common Lighting Design Metrics for Predicting Human Visual Comfort in Offices with Daylight. Leikos 2014, 10, 145-164. [CrossRef]

12. Bellia, L.; Spada, G.; Pedace, A.; Fragliasso, F. Methods to evaluate lighting quality in educational environments. Energy Procedia 2015, 78, 3138-3143. [CrossRef]

13. Costanzo, V.; Evola, G.; Marletta, L. A review of daylighting strategies in schools: State of the art and expected future trends. Buildings 2017, 7, 41. [CrossRef]

14. Leccese, F.; Salvadori, G.; Rocca, M.; Buratti, C.; Belloni, E. A method to assess lighting quality in educational rooms using analytic hierarchy process. Build. Environ. 2020, 168, 106501. [CrossRef]

15. Leccese, F.; Salvadori, G.; Rocca, M. Visual discomfort among university students who use CAD workstations. Work 2016, 55, 171-180. [CrossRef] [PubMed]

16. Chiou, Y.S.; Huang, P.C. An HDRi-based data acquisition system for the exterior luminous environment in the daylight simulation model. Soil. Energy 2015, 111, 104-117.

17. Ward, G. Photosphere Software 2005. Available online: http://www.anyhere.com/ (accessed on 20 March 2020).

18. Doyle, S.; Reinhart, C.; High Dynamic Range Imaging \& Glare Analysis II. HDR Photography suing Photosphere, Lecture Note at Harvard Graduate School of Design. 2010. Available online: http://web.mit.edu/ sustainabledesignlab/projects/TeachingResources/HDR_II_Photosphere.pdf (accessed on 20 March 2020).

19. Kumaragurubaran, V.; Inanici, M. Hdrscope: High dynamic range image processing toolkit for lighting simulations and analysis. In Proceedings of the the BS2013: 13th Conference of International Building Performance Simulation Association, Chambéry, France, 26-28 August 2013; pp. 3400-3407.

20. Hdrscope Software. Available online: http://courses.washington.edu/hdrscope/index.html (accessed on 20 March 2020).

21. Wienold, J.; Christoffersen, J. Evaluation methods and development of a new glare prediction model for daylight environments with the use of CCD cameras. Energ Build. 2006, 38, 743-757. [CrossRef]

22. Suk, J.; Schiler, M. Investigation of Evalglare software, daylight glare probability and high dynamic range imaging for daylight glare analysis. Light. Res. Technol. 2013, 45, 450-463. [CrossRef]

23. Suk, J.Y. Luminance and vertical eye illuminance thresholds for occupants' visual comfort in daylit office environments. Build. Environ. 2019, 148, 107-115. [CrossRef]

24. Pierson, C.; Wienold, J.; Bodart, M. Daylight Discomfort Glare Evaluation with Evalglare: Influence of Parameters and Methods on the Accuracy of Discomfort Glare Prediction. Buildings 2018, 8, 94. [CrossRef]

25. EN12464-1 Lighting of Indoor Workplaces; European Committee for Standardization: Brussels, Belgium, 2011.

26. CNS Standards 12112: Lighting for Indoor Work Places; Bureau of Standards, Metrology and Inspection, Taiwan Ministry of Economic Affairs: Taipei City, Taiwan, 2012.

27. Manual of Lighting Energy Efficiency Improvement in School; Taiwan Ministry of Education: Taipei City, Taiwan, 2012.

(C) 2020 by the authors. Licensee MDPI, Basel, Switzerland. This article is an open access article distributed under the terms and conditions of the Creative Commons Attribution (CC BY) license (http://creativecommons.org/licenses/by/4.0/). 